\title{
Developing an Approach for Generating a Spatial Urban Health Equity Map and Validating via Volunteered Geographic Information
}

zeinab neisani samani ( $\sim$ zeinab.neisani@srbiau.ac.ir )

Islamic Azad University

Mohammad Karimi

KN Toosi University of Technology

Aliasghar Alesheikh

KN Toosi University of Technology

Najmeh neisani Samany

University of Tehran

\section{Research}

Keywords: Spatial health equity, Volunteered geographic information (VGI), Accessibility, Fuzzy inference system (FIS), Health care and medical centers (HCMCs)

Posted Date: July 29th, 2020

DOI: https://doi.org/10.21203/rs.3.rs-49048/v1

License: (9) This work is licensed under a Creative Commons Attribution 4.0 International License. Read Full License 


\title{
Developing an Approach for Generating a Spatial Urban Health Equity Map and Validating via Volunteered Geographic Information
}

\author{
Zeinab Neisani Samani ${ }^{1}$, Mohammad Karimi ${ }^{2}$, Aliasghar Alesheikh ${ }^{* 2}$, Najmeh neisani Samany ${ }^{3}$ \\ ${ }^{1}$ Department of RS/GIS, Science and Research Branch, Islamic Azad University, Iran; \\ zeinab.neisani@srbiau.ac.ir. \\ ${ }^{2}$ Department of GIS, Faculty of Geodesy and Geomatics Engineering, K. N. Toosi University of \\ Technology, Iran; mkarimi@kntu.ac.ir; alesheikh@kntu.ac.ir. \\ ${ }^{3}$ Department of Remote Sensing and GIS, Faculty of Geography, University of Tehran, Iran; \\ nneysani@ut.ac.ir.
}

\begin{abstract}
Spatial urban health equity assessment is of vital importance, relating closely to quality of life standards and level of urban development. Generally, spatial health equity can be assessed according to spatial accessibility to health care and medical centers (HCMCs), green spaces, public transportation stations and main roads. The density and distribution of HCMCs are also important factors in spatial health equity assessment and air pollution level can also affect the health of citizens. This paper aims to model the spatial urban health equity map by aggregating all these criteria using reference data. Then, it compares the health equity map generated from reference data to one generated by volunteered geographic information (VGI) by citizens. The main contributions of this paper include i) aggregating spatial accessibility criteria, density and distribution of HCMCs and air pollution levels, based on the Mamdani fuzzy inference system (FIS), ii) comparing the spatial equity map with a health equity map achieved using VGI. Health equity status of citizens was categorized into five levels from 'very appropriate' to 'very inappropriate' and collected by citizens using a VGI website. The proposed method was implemented in District 6 of Tehran, Iran. Our findings showed for the resulting map with the reference data that almost $62 \%$ of the study area, was reported as 'appropriate or 'very appropriate', $20 \%$ as 'good' and about $18 \%$ as 'inappropriate' or 'very inappropriate'. The collected VGI from citizens achieved results with $72 \%$ compatibility. Furthermore, according to the precision, recall and F-score measures, most accuracy was attributed to the 'appropriate' level of spatial health equity and the least accuracy to the 'very inappropriate' level.
\end{abstract}

Keywords: Spatial health equity, Volunteered geographic information (VGI), Accessibility, Fuzzy inference system (FIS), Health care and medical centers (HCMCs). 


\section{Introduction}

Equity of access to health care services and providing a healthy environment for citizens is one of the main objectives of sustainable urban planning (Lu et al., 2019). Health equity is widely proclaimed to be an important goal of public health policy and practice. The health system, urban planning and policies can influence population health both to reduce or exacerbate inequities (Corburn and Cohen, 2012; Whitehead et al., 2019). Equity in the use of health care services is an issue, which has increasingly been on the health policy agenda in recent years in both middle- and low-income countries. Distribution of resources within the health care sector may follow many different paths depending on the stated aims or goals of the health system (Mishra et al., 2019; Neisani Samani and Alesheikh, 2019; Whitehead et al., 2019). Utilitarian principles dictate that resources should be allocated in such a way that one can maximize the overall health and wellbeing of society.

The development of health care facilities in a nation improves the quality of life of its citizens and enhances their efficiency and productivity (Mishra et al., 2019). Many countries experience systematic and unfair differences in health, called health inequities (Whitehead et al., 2019). While recognizing the importance of factors such as the quality of health care and discrimination, ensuring the spatial equity of health services is a core step to achieving equity (Harris et al., 2013).

There are different criteria affecting the health status of people. Accessibility to health care and medical centers (HCMCs) is one of the main factors of spatial health equity. An individual might be physically incapable of traveling the distances required to reach health care services, or long distances can make seeking regular care unappealing despite the potential benefits (Banerjee and Duflo, 2011). This paper considered six criteria in assessing spatial accessibility including footpath distance to HCMCs, travel time to HCMCs, level of nearest service (Dehbareza et al., 2018), distance to main roads, distance to green spaces (Hunter et al., 2019) and distance to public transportation. The spatial accessibility map was prepared using a weighted linear combination (WLC) method (Malczewski, 2011), through weighting the criteria using the analytic hierarchy process (AHP).

The other important factors in spatial urban health equity assessment are the density and distribution of HCMCs (Zhang and Lee, 2014). In addition, nowadays, the level of air pollution in a region can cause poor health (Pierangeli et al., 2020). To achieve the spatial urban health equity 
map, four derived maps of spatial accessibility, density, distribution and air pollution have been aggregated using the Mamdani fuzzy inference system (FIS). With the aim of validating the achieved results, a web-based participatory geographic information system (GIS) has been developed to collect information voluntarily submitted by citizens on health equity and citizens' locations (Mooney et al., 2013).

The main contributions of this paper include: i) aggregating spatial accessibility criteria, density and distribution of HCMCs and air pollution levels, based on the Mamdani FIS, ii) comparing the spatial equity map with a health equity map achieved using VGI. The proposed method was implemented in District 6 of Tehran. The experimental results showed that the northwest and northeast of District 6 generally suffers from inappropriate access to HCMCs while the south part has appropriate access.

According to the density and distribution of HCMCs and air pollution levels in these areas, spatial equity varies, the health equity status is very associated with the accessibility map.

The remainder of this paper is organized as follows: in section 1.1, a literature review is presented. In section 1.2, the study area is described. Section 2 focuses on the proposed method, assumptions and notations. Section 3 presents the experimental results and discussion. Finally, section 5 presents concluding remarks and proposes future studies.

Based on the idea of spatial justice, the study of spatial equity in urban public facilities has been considered as one a hot topic in recent years. With the vital role of HCMCs in urban planning, the assessment of spatial health equity is an important issue. Usually, the main component of spatial urban health equity is spatial health accessibility.

Earlier studies have used gravity-based accessibility measures (Koenig, 1980) and ratio processes (Joseph and Bantock, 1982) for accessibility assessment. Recently the GIS-based method and spatial analysis have provided promising results for spatial health accessibility (Giuliano and Kang, 2018; Shin and Lee, 2018; Tobias et al., 2015; Wang, 2018) accurately modeling residents' access to health facilities in big cities (Lättman et al., 2018; Lee and Miller, 2019). Compared to other methods, this kind of method takes into account the most comprehensive factors. In these studies, the GIS-based multi-criteria decision analysis (MCDA) (Dell'Ovo et al., 2018; Alzouby et al., 2019) has been used effectively, supporting collation of different criteria rated by their importance. 
Mansour (2016) studied ratios and accessibility to public health facilities in the population of Saudi Arabia. The spatial patterns of service distribution and distance from people to facilities were examined using an average nearest neighbor method. Several districts were identified as underserved by public health facilities and many districts were identified with low public health provision. The spatial pattern of accessibility in rural areas of Henan Province, China, has also been comprehensively analyzed via spatial analysis and coefficient of variation (Liu et al., 2019). The spatial incongruity of influencing criteria was assessed using the geographically weighted regression model.

Whitehead et al. (2019) examined spatial justice and access to health care in New Zealand. The study used binomial logistic regression to examine factors from the records of patients referred to health centers and thus bypassing medical services closer to patients' homes. This study suggests that the closest distance accessibility measure may be inappropriate in mixed urban-rural settings. Shaoyao et al. (2019) propose a demand-driven '2R grid-to-level' method of analyzing the spatial equity in access to a multilevel health care system in Chengdu. The results indicated that significant differences exist in spatial accessibility to different levels of health care. Neisani Samani and Alesheikh (2019) improved an approach that could identify inequity in health care services based on citizens' preferences. The decision-making process in this situation considered the uncertainties that exist in any steps of decision-making using the Fuzzy-VIKOR method.

Though spatial accessibility is a core factor influencing spatial health equity, the density and distribution of HCMCs are considered as effective criteria for spatial health equity assessment (Mansour, 2016; Ni et al., 2016; Ramzia and El-Bedawi, 2019). Air pollution is also considered an important factor in health equity of citizens and has a significant role in spatial health equity (Pierangeli et al., 2020; Kurata et al., 2020). A review of the relevant literature revealed that the availability, density and distribution of HCMCs and air pollution from one area have not yet been studied in combination.

On the other hand, VGI as another GIS-based technology presents a new generation of health equity maps. Based on participation of people, 'citizen sensors' the data offer a window into people's insights and understandings of health and place that may be hard to gather from organizational datasets (Levere et al., 2019). Kolak et al. (2020) demonstrated a participatory asset mapping infrastructure developed with a Chicago community using VGI concepts, participatory 
design principles and geospatial software as a service using a suite of free and/or open source tools. The main lack of these methods is that they ignore a comprehensive framework for spatial equity mapping; they were mostly focused on spatial health accessibility, not on density, distribution and air pollution. McLafferty et al. (2020) propose a conceptual framework that describes the interacting effects of socioeconomic, behavioral, geographic and technological processes on VGI accuracy and credibility. They used GIS and statistical methods to analyze social and geographical biases in health-related VGI through a case study of bed bug complaint data from New York City's 311 system. They concluded that using VGI for modeling health equity status could entail time, financial and opportunity costs.

\section{Methods}

This section describes the method used to prepare a spatial equity map, which comprises a sixstage process as presented in Fig. 1, which involves:

a) Generating a health accessibility map, by integrating six effective criteria using WLC.

b) Producing an air pollution map, by interpolating the air quality index of pollution sensing stations based on the Kriging interpolation approach.

c) Creating density and distribution maps of HCMCs.

d) Aggregating the three generated maps using FIS.

e) Creating a health equity map, provided via VGI. The spatial distribution of healthy and unhealthy citizens was generated using inverse distance weighting (IDW) on VGI.

f) Comparing the maps generated from FIS and VGI. 


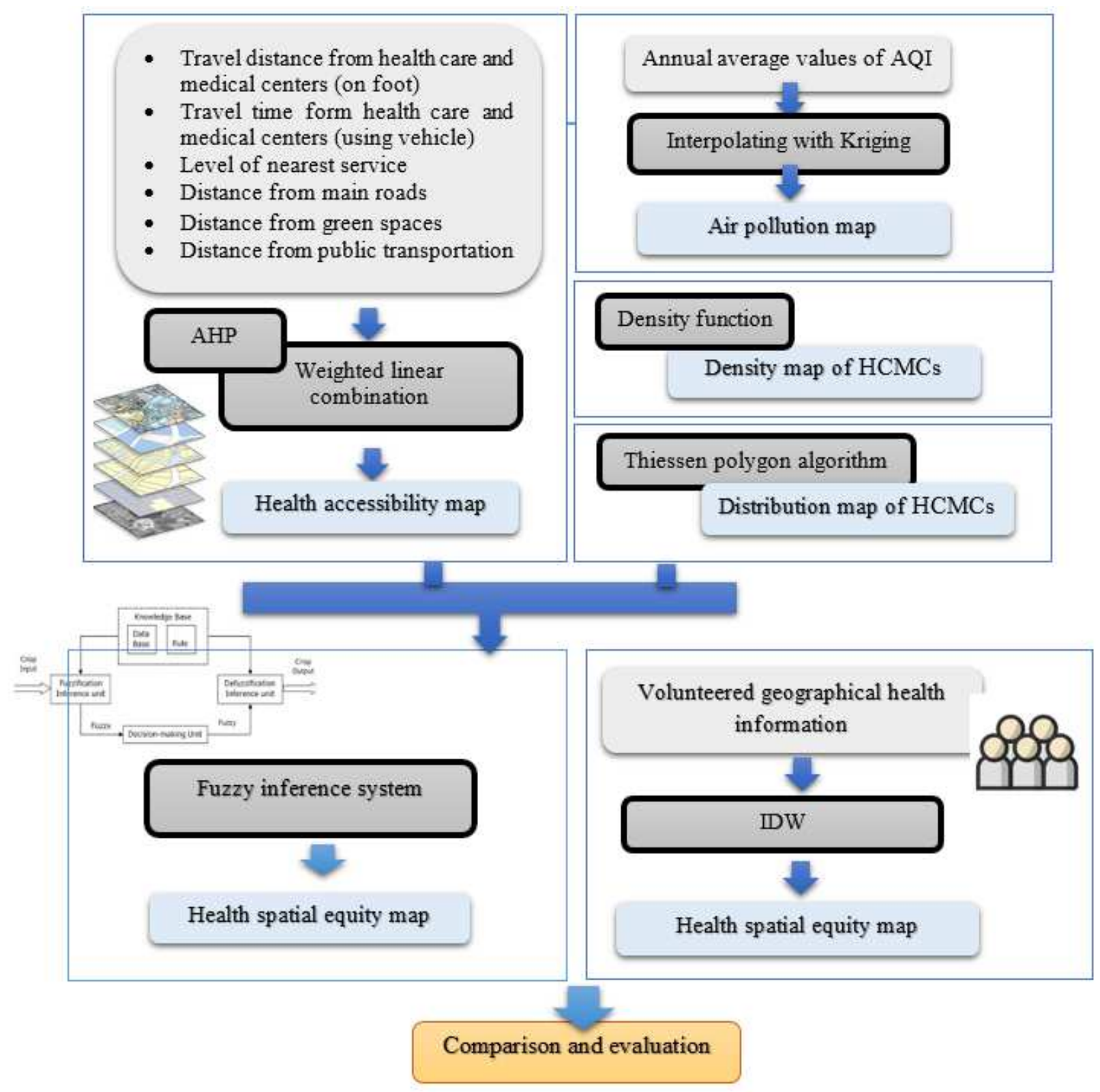

Fig. 1. Flowchart of the methodology.

\subsection{Study Site}

The study area of this paper was District 6 of Tehran, in the capital of Iran, which is geographically located in the center of Tehran (Fig. 2). There are 12 hospitals and 68 medical centers in this district. It has about $29 \%$ residential use and more than $30 \%$ of the area is occupied by offices and 
commercial centers. It is one of the most polluted areas of Tehran due to the high volume of traffic for work, education and entertainment purposes.

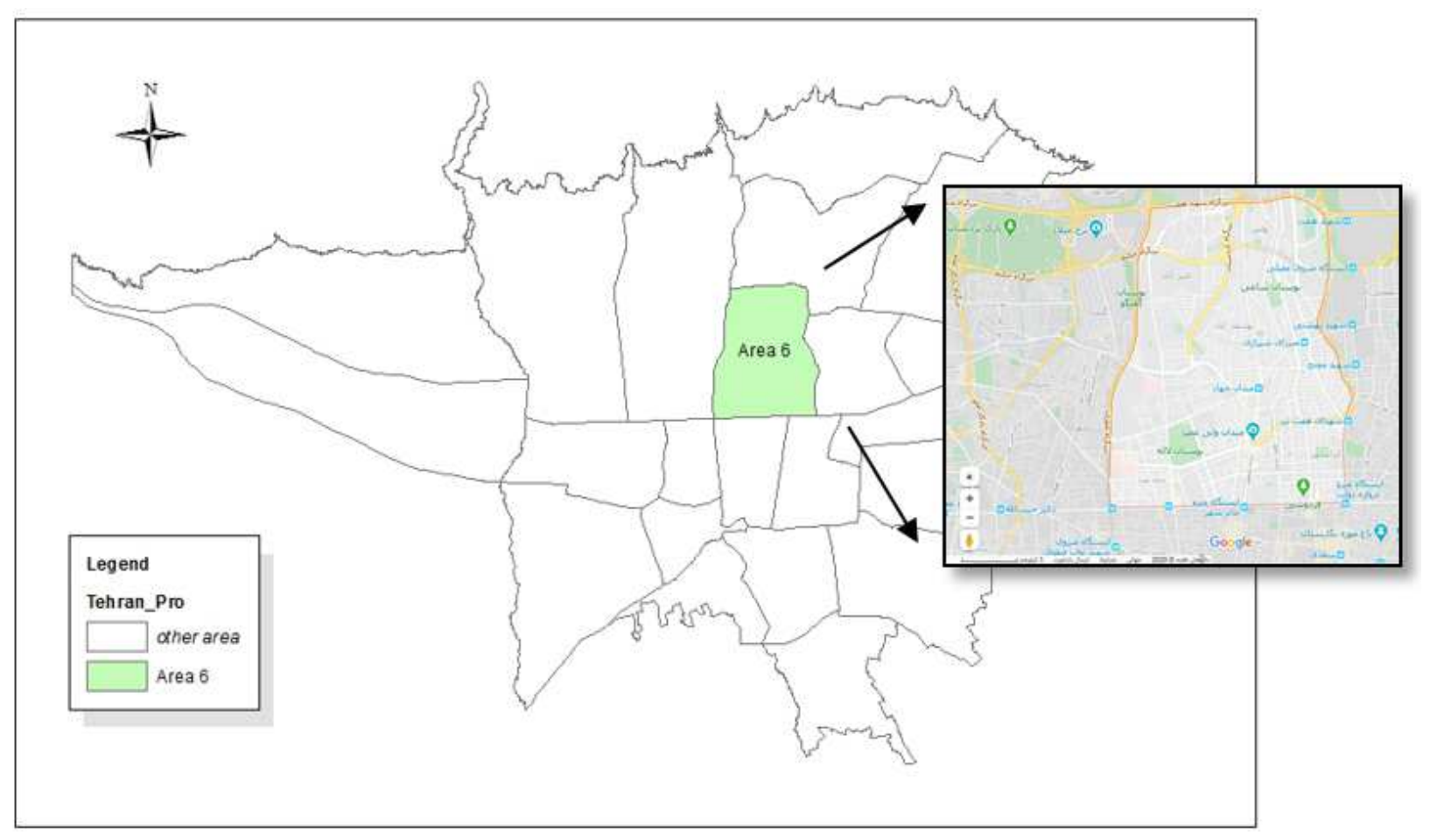

Fig. 2. The study area (District 6 of Tehran).

\subsection{Health Accessibility Map}

To ensure adequate access to urban facilities, it's important for urban planners to realize equity in the geographical arrangement of such facilities (Ashik et al., 2019). Spatial accessibility is commonly defined in terms of distance, where shorter distance denotes greater accessibility (Powell et al., 2006; Moore et al., 2008; Todd et al., 2015; Fan et al., 2017). In health-related sciences, access to HCMCs including hospitals, clinics, pharmacies, emergency departments, etc. is one of the major indices of health equity.

According to the literature (Hartig et al., 2014; Helbich, 2018; Cole et al., 2019), six main parameters are effective in producing spatial health accessibility including: (i) travel distance to HCMCs (on foot), (ii) travel time to HCMCs (using a vehicle), (iii) level of the nearest service, 
(iv) distance to main roads, (v) distance to green spaces and (vi) distance to public transport stations. All these parameters are described in Table 1.

\section{Table 1}

Description of health accessibility parameters.

No. Health accessibility parameters

\begin{tabular}{|c|c|c|}
\hline 1 & $\begin{array}{l}\text { Travel distance to health care } \\
\text { and medical centers (on foot) }\end{array}$ & $\begin{array}{l}\text { Walkable distance to health care centers is important } \\
\text { for citizens }\end{array}$ \\
\hline 2 & $\begin{array}{l}\text { Travel time to HCMCs (using a } \\
\text { vehicle) }\end{array}$ & $\begin{array}{c}\text { Access time which describes temporal cost of travel } \\
\text { distance }\end{array}$ \\
\hline 3 & Level of nearest service & $\begin{array}{l}\text { All citizens should have appropriate access to } \\
\text { different levels of health service }\end{array}$ \\
\hline 4 & Distance to main roads & $\begin{array}{l}\text { Minimum distance of medical centers to a main road } \\
\text { is important in health equity }\end{array}$ \\
\hline 5 & Distance to green spaces & $\begin{array}{l}\text { Access to green spaces including urban parks and } \\
\text { gardens is a common health-related factor in cities } \\
\text { Access to green spaces has a positive impact on } \\
\text { health }\end{array}$ \\
\hline 6 & Distance to public transport & $\begin{array}{l}\text { Access to public transport services including bus } \\
\text { stations, metro stations, subways and taxies is } \\
\text { necessary for patients, so this is important to assess } \\
\text { health equity }\end{array}$ \\
\hline
\end{tabular}

\subsection{Weighted Linear Composition (WLC)}

WLC is one of the common techniques in MCDA which is based on the weighted average concept The decision-maker gives weights to the criteria directly based on the relative importance of each criterion (Malczewski, 2011). By multiplying the relative weight by the value of that criterion, a final value is obtained for each alternative. After the final value of each alternative is determined, 
the alternatives with the highest values are considered most relevant. With this method, the decision rule calculates the value of each alternative by Eq. (1) with the following relation: in the WLC model, two components of the value of functions $\mathrm{V}\left(\mathrm{a}_{i k}\right)$ and the weight of criteria $\left(\mathrm{W}_{k}\right)$ are used and calculated using:

$$
V\left(A_{i}\right)=\sum_{k=1}^{n} W_{k} \mathrm{~V}\left(\mathrm{a}_{i k}\right)
$$

where $\mathrm{V}\left(\mathrm{a}_{i k}\right)$ is the value of cell $\mathrm{i}$ according to the criterion $\mathrm{k}, \mathrm{W}_{k}$ is the weight of criterion $\mathrm{k}$, $\mathrm{V}\left(\mathrm{A}_{\mathrm{i}}\right)$ is the final value of output cell $\mathrm{i}$ and $\mathrm{n}$ is the number of criteria (Malczewski, 2000).

\subsection{Analytic Hierarchy Process (AHP)}

AHP is formulated to design a decision procedure in a set comprising different independent factors. With this approach, a complex problem can be categorized into several sub-problems that are mapped into hierarchical levels and each level contains a set of criteria or attributes. The first level of the hierarchy represents the goal of the problem and the middle levels show the criteria of the corresponding upper levels. The lowermost level comprises the alternatives or actions measured when attaining the goal. AHP compares the factors (Saaty, 1980, 2005; Saaty and Vargas, 1991). According to studies by Saaty and Vargas (1991), the suggested comparison range of criteria is between 1 and 9. Each digit within this range represents the relative importance of the corresponding unit: ' 1 ' specifies similar (equal) importance and '9' indicates substantial superiority of one criterion over another. AHP is designed in four steps:

1. In the first stage, the complicated problems convert into simpler ones, which is a hierarchical presentation of a real-world complex problem, wherein the ultimate objective of the problem is at its highest level, followed by criteria, sub-criteria and alternatives at the lower levels.

2. In this step, pairwise comparisons among criteria are completed. An $n^{*} n$ pairwise comparison matrix is constructed based on Eq. 2:

$$
A=\left(\begin{array}{cccc}
a 11 & a 12 & \ldots & a 1 n \\
a 21 & a 22 & \ldots & a 2 n \\
\ldots & \ldots & \ldots & \ldots \\
a n 1 & a n 2 & \ldots & a n n
\end{array}\right)
$$


In the pairwise comparison matrix, the main diagonal of the matrix is ' 1 ' and each component above the main diagonal is the reverse of its matched component under the main diagonal.

3. In this step, all components in each column of the pairwise comparison matrix are summed up and each component's value is divided by the sum of the values of the elements in its column (Eq. 3).

$$
\mathrm{AW}=\left(\begin{array}{cccc}
\frac{\mathrm{a}_{11}}{\sum a_{i 1}} & \frac{\mathrm{a}_{12}}{\sum a_{i 2}} & \cdots & \frac{\mathrm{a}_{1 n}}{\sum a_{i n}} \\
\frac{\mathrm{a}_{21}}{\sum a_{i 1}} & \frac{\mathrm{a}_{22}}{\sum a_{i 2}} & \cdots & \frac{\mathrm{a}_{2 n}}{\sum a_{i n}} \\
\cdots & \cdots & \cdots & \cdots \\
\frac{\mathrm{a}_{n 1}}{\sum a_{i 1}} & \frac{\mathrm{a}_{22}}{\sum a_{i 2}} & \cdots & \frac{\mathrm{a}_{n n}}{\sum a_{i n}}
\end{array}\right)
$$

Then, the average value is computed for each row of the normalized matrix and the weight vector for the parameters are achieved as a C matrix (Eq. 4):

$$
\mathrm{C}=\left[\begin{array}{l}
C 1 \\
C 2 \\
\cdots \\
C n
\end{array}\right]=\left(\begin{array}{cccc}
\frac{a 11}{\frac{\sum a i 1}{n}} & \frac{a 12}{\sum a i 2} & \cdots & \frac{a 1 n}{n a i n} \\
\frac{a 21}{n a i 1} & \frac{a 22}{\sum a i 2} & \cdots & \frac{a 2 n}{n} \\
\frac{\sum a i n}{n} & \frac{1}{n} \\
\frac{a n 1}{\frac{\sum a i 1}{n}} & \frac{a n 2}{\sum a i 1} & \cdots & \frac{a n n}{n} \\
\frac{\sum a i 1}{n}
\end{array}\right)
$$

4. To compute the consistency ratio (CR), the pairwise comparison matrix (A) is multiplied by the weight vector (C) to produce a suitable estimate (Eq. 5):

$$
\mathrm{A} \times \mathrm{C}=\left(\begin{array}{cccc}
\mathrm{a}_{11} & \mathrm{a}_{12} & \ldots & \mathrm{a}_{1 n} \\
\mathrm{a}_{21} & \mathrm{a}_{22} & \ldots & \mathrm{a}_{2 n} \\
\ldots & \ldots & \ldots & \ldots \\
\mathrm{a}_{n 1} & \mathrm{a}_{22} & \ldots & \mathrm{a}_{n n}
\end{array}\right) \times\left[\begin{array}{c}
\mathrm{C}_{1} \\
\mathrm{C}_{2} \\
\ldots \\
\mathrm{C}_{n}
\end{array}\right]=\left[\begin{array}{c}
\mathrm{x}_{1} \\
\mathrm{x}_{2} \\
\ldots \\
\mathrm{X}_{n}
\end{array}\right]
$$

The consistency index $(\mathrm{CI})$ - applied for calculating $\mathrm{CR}$ - is computed in the same way Eq. 6: 


$$
\mathrm{CI}=\frac{\lambda \max -\mathrm{n}}{\mathrm{n}-1}
$$

where $\mathrm{n}$ is the number of criteria i.e., the dimensions of matrix $\mathrm{A}$ and $\lambda_{\max }$ is the highest eigenvalue of matrix A. The consistency ratio is computed by Eq. (7):

$$
C R=\frac{\mathrm{CI}}{\mathrm{RI}}
$$

In order to verify as the consistency index (CI) is adequate, the consistency rate (CR), which is decided by the ratio between the consistency index and therefore the random consistency index (RI) (Saaty, 2005). If the consistency ratio is $=<0.1$, the system has acceptable consistency; if the ratio is greater than 0.1 , the decision-makers should revise their judgments (Saaty, 2008).

\subsection{Normalization of Criteria}

As the criteria are related to different data sources, they have different units and should be changed to comparable units for suitability maps. To normalize the data (converting the data range to between 0 and 1) usually the Eqs. (8) and (9) are used.

$$
\begin{aligned}
\operatorname{vmax}_{i j} & =\frac{\mathrm{X}_{i j}-\mathrm{X}_{\text {imin }}}{\mathrm{X}_{j \max }-\mathrm{X}_{j \min }} \\
\operatorname{vmin}_{i j} & =\frac{\mathrm{X}_{j \max }-\mathrm{X}_{i j}}{\mathrm{X}_{j \max }-\mathrm{X}_{j \min }}
\end{aligned}
$$

where, $\operatorname{vmax}_{i j}$ is the normalized value of maximized criterion, $\operatorname{vmin}_{i j}$ is the normalized value of minimized criterion, $\mathrm{X}_{i j}$ is the raw value for the location $\mathrm{i}$ and the indicator $\mathrm{j}, \mathrm{X}_{j m i n}$ represents the minimum value for the indicator $\mathrm{j}$ and $\mathrm{X}_{\text {jmax }}$ is the maximum value for the indicator $\mathrm{j}$.

\subsection{Density and Distribution of HCMCs}

The other measures to model spatial equity are the density and distribution of HCMCs (Richardson et al., 2012; Ashik et al., 2019). Density is related to the number of HCMCs per $\mathrm{km}^{2}$. Spatial distribution is calculated based on the proportion of HCMCs in each municipal sector in a district. 


\subsection{Air Quality Index (AQI)}

The AQI index is a measure of air quality reported daily indicating how clean or polluted the air is. This factor also has effects on citizens' health. The AQI is calculated based on five major air pollutants, including speck pollution, carbon monoxide, earth-surface ozone, sulfur dioxide and nitrogen dioxide. The environmental protection agency (EPA) recommends nationwide air quality limits for each of these contaminants to protect public health. The purpose of the AQI is to monitor local air quality and understand its impact on human health (Habibi et al., 2017). To make it easier to understand, the AQI is divided into six categories as depicted in Table 2:

\section{Table 2}

Six categories of AQI values and related health levels.

\begin{tabular}{cc}
\hline AQI Values & Health Level \\
\hline $0-50$ & Good \\
\hline $51-100$ & Moderate \\
\hline $101-150$ & Unhealthy for vulnerable groups \\
\hline $151-200$ & Unhealthy \\
\hline $201-300$ & Very unhealthy \\
\hline $301-500$ & Hazardous \\
\hline
\end{tabular}

These six levels of health concern are described as follows:

- Good: AQI is between 0 and 50 . Air quality is measured as satisfactory and the air pollution poses no or a slight risk.

- Moderate: AQI is between 51 and 100. The contamination is small, although, for some pollutants, there may be a reasonable health worry for a few individuals.

- Unhealthy for vulnerable Groups: AQI is between 101 and 150 . Vulnerable groups may be affected, including individuals with lung illnesses, children and senior citizens.

- Unhealthy: AQI is between 151 and 200. There may be detrimental health effects for all citizens.

- Very Unhealthy: AQI is between 201 and 300. Air pollution may cause serious health effects for everyone.

- Hazardous: AQI is higher than 300 . The health effects are hazardous to all citizens. 


\subsection{Kriging Interpolation}

Given the values $\mathrm{c}=\left\{\mathrm{c}\left(\mathrm{p}_{1}\right), \mathrm{c}\left(\mathrm{p}_{2}\right), \ldots, \mathrm{c}\left(\mathrm{p}_{\mathrm{n}}\right)\right\}$ as a limited set of $\mathrm{n}$ input points denoted by $\mathrm{p}=\left\{\mathrm{p}_{1}\right.$, $\left.\mathrm{p}_{2}, \ldots, \mathrm{p}_{\mathrm{n}}\right\}$, a linear approximation of the values $\hat{C}=\left\{\hat{C}\left(p_{t 1}\right), \hat{C}\left(p_{t 2}\right), \ldots, \hat{C}\left(p_{t m}\right)\right\}$ at $\mathrm{m}$ target points $\mathrm{p}_{\mathrm{t}}=\left\{\mathrm{p}_{\mathrm{t} 1}, \mathrm{p}_{\mathrm{t} 2}, \ldots, \mathrm{p}_{\mathrm{tm}}\right\}$ is calculated by Eq.10 (Zhong et al., 2016):

$$
\hat{C}=W^{T} C
$$

where $W \in R^{n \times m}$ are the linear weights. Ordinary Kriging is the linear unbiased estimator which confirms the zero mean and the minimum variance of the estimation error. Resolving the optimization issue results in Eq. (11) (Zhong et al., 2016):

$$
\left[\begin{array}{cc}
C_{p p} & 1_{n} \\
1_{n}^{T} & 0
\end{array}\right]\left[\begin{array}{l}
W \\
\mu^{T}
\end{array}\right]=\left[\begin{array}{c}
C_{p p t} \\
1_{m W}^{T}
\end{array}\right]
$$

where $C_{x y} \in \mathbb{R}^{|x|} \times|y|$ shows the covariance matrix amid two specified point sets $\mathrm{x}$ and $\mathrm{y},|(\cdot)|$ indicates the cardinality of $(\cdot), 1_{n} \in \mathrm{R}$ is related to the column vector of all ones, ${ }^{\top}$ represents the matrix transpose process and $\mu \in \mathrm{R}^{\mathrm{m}}$ shows the Lagrange multiplier. Although the kernel matrix (left square matrix) of the linear system of Eq. (11) is not positive definite (a diagonal element is 0 ), a legal spatial covariance model must confirm that $\mathrm{C}_{\mathrm{pp}}$ is the asymmetric positive definite matrix (Myers,1994), that could be reversed more competently by means of the Cholesky decomposition than via any other approach. Hence the weights can be computed more efficiently as Eq. 12 (Zhong et al., 2016):

$$
W=\left(C_{p p}^{-1}+\frac{1}{C} C_{p p}^{-1} 1_{n} 1_{n}^{T} C_{p p t}^{-1}\right) C_{p p t}-\frac{1}{c} C_{p p}^{-1} 1_{n} 1_{m}^{T}
$$

where $c=-1_{n}^{T} C_{p p}^{-1} 1_{n} . \widehat{Z}$ could be achieved by replacing Eq.12 with Eq. 10 (Zhong et al., 2016).

$$
\hat{Z}=C_{p p t}^{T} \tilde{W}-\tilde{c}
$$

where $\widetilde{W}=\left(C_{p p}^{-1}+\frac{1}{C} C_{p p}^{-1} 1_{n} 1_{n}^{T} C_{p p t}^{-1}\right) Z$ and $\tilde{c}=\frac{1}{c} C_{p p}^{-1} 1_{n} 1_{m}^{T}$.

\subsection{Generating Spatial Health Equity Map Using VGI}

VGI supports the gathering, access and propagation of geographic information by human volunteers across the Internet (Mooney et al., 2013), providing real-time data from simple data collection procedures, especially useful for health data (Neisani Samani et al., 2020). VGI offers numerous advantages: it is low-cost and often free of charge and collects local and up-to-date information that would otherwise be impossible to collect (Goodchild and Li, 2012). GIS context 
is measured as a consistent platform for recognizing the accurate location of VGI services (Neisani Samani et al., 2020).

In this paper, first the spatial health equity status data of each arbitrary location is entered using the VGI platform (designed spatial website) by volunteer citizens; citizens enter the level of spatial health equity in their location. Levels are integers (1-5), where 1 indicates 'very appropriate' and 5 indicates 'very inappropriate' and the integers between reflect the scale of appropriateness in between.

The spatial health equity map is generated using IDW (Zhang and Lee, 2014), which estimates the value of a non-assigned location via a linear combination of values at assigned locations (points that are registered by citizens) weighted by an inverse function of the distance from the nonassigned location to the assigned locations as expressed in Eq. 14:

$$
X_{i}=\frac{\sum_{i=1}^{n} x_{i} / d_{i}^{p}}{\sum_{i=1}^{n} 1 / d_{i}^{p}}
$$

where $\mathrm{X}$ is the interpolated value, $\mathrm{d}_{\mathrm{i}}$ is the distance amid non-assigned value $\mathrm{x}_{0}$ and the assigned value $x_{i}, p$ is a power which is considered ' 2 ' in this paper (generally used; Zhang and Lee, 2014) and $\mathrm{n}$ represents the number of assigned locations for approximating (Webster and Oliver, 2007).

\subsection{Aggregating Maps Using Fuzzy Inference System (FIS)}

Fuzzy logic is a successful application of fuzzy set theory, in which the variables are linguistic instead of arithmetic and was first presented by Lotfi Zadeh (1965). The key to understanding the difference between fuzzy sets and classic sets is the concept of the membership degree. In classical logic, membership to a conceptual set is quite definite and precise. Therefore, an object is a member of a crisp set or not (Neisani Samani et al., 2014). However, in fuzzy logic, the membership function takes continuous values between 0 and 1 as a membership degree, which can be described by Eq. 15:

$$
\tilde{\mathrm{A}}=(\mathrm{x}, \mu \tilde{\mathrm{A}}(\mathrm{x}) \mid \mathrm{x} \in \mathrm{U}\}
$$

where $\tilde{\mathrm{A}}$ is a fuzzy set from universe $\mathrm{U}, \mathrm{x}$ is a value and $\mu \tilde{\mathrm{A}(\mathrm{x})}$ is the membership degree of $\mathrm{x}$ in $\tilde{\mathrm{A}}$. 
FIS comprises four main elements (Lee, 1990): a fuzzification interface, a rule-based, inference engine and a defuzzification interface. The procedure of changing explicit variables into linguistic variables is called fuzzification. The set of fuzzy rules is called a fuzzy rule-base. The inference engine assesses and infers the rules with inference algorithms and translates them into numeric values after the output rules are aggregated (Neisani Samani et al., 2020). The defuzzification is usually done using the center of gravity area (COA) method. This paper also utilized the form Max-Min inference approach proposed by Mamdani (1977): the formulation of centroid of Mamdani inference system is stated as Eq.16:

$$
z_{C O A}=\frac{\int_{Z} \mu_{A}(z) z d z}{\int_{z} \mu_{A}(z) d z}
$$

where $Z_{\mathrm{COA}}$ is the defuzzied value, $\mathrm{z}$ is the value of the variable and $\mu_{\mathrm{A}}$ is the aggregated output MF. This is the most widely adopted defuzzification strategy, which is reminiscent of the computation of expected values of eventuality distributions.

\section{Results}

This paper used two implementation guidelines. The first procedure (producing a spatial health equity map using reference data) was performed on a personal computer using ArcGIS 10.3 software. The second process (generating a spatial health equity map using VGI) was developed using client-server architecture (Fig. 3). The server comprised a geospatial database and the GIS server. The GIS server applied GeoServer. Consistent with the system architecture, Postgres SQL (PostGIS) was used as the geospatial database management system to store the geospatial data and VGI. 


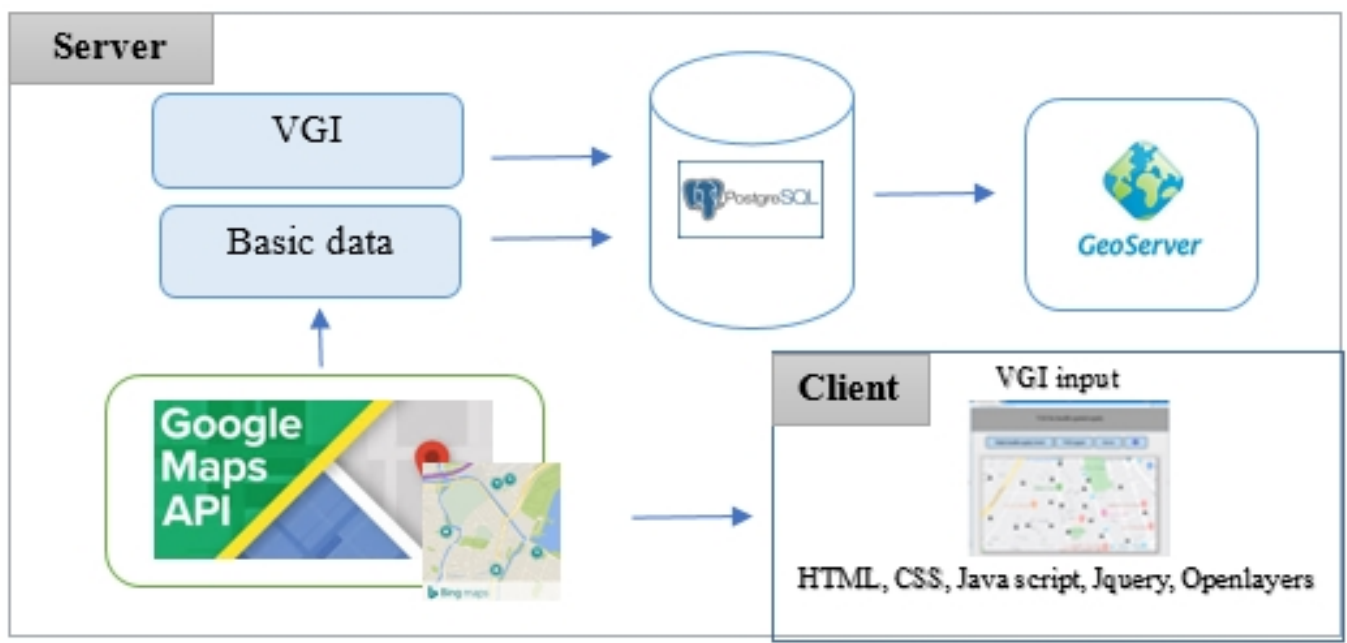

Fig. 3. The architecture of VGI system.

\subsection{Mapping of Spatial Equity Map}

Three basic datasets were used in this research to establish a spatial equity map. First, spatial data were used to create an accessibility map. The second dataset was related to the raster air pollution map, which was achieved by interpolating monitoring stations' data. The third map was achieved using the VGI-based input.

\subsubsection{Providing Health Accessibility Map}

To achieve a spatial health accessibility map, the weights of criteria were computed based on expert knowledge. Information was collected from experts by questionnaire and interview. The experts were 14 physicians, 14 urban planners and 22 patients. The mentioned criteria and sub-criteria were eventually prioritized and ranked at different levels based on expert opinion. Each criterion or sub-criterion was prioritized based on its relevance to the decision-making objective. AHP was then applied to obtain the final weights for the criteria and sub-criteria at each level as shown in Table 3.

\section{Table 3}

Weights assigned to different criteria.

\begin{tabular}{lll}
\hline Criteria & Weight & CR \\
\hline Travel distance from HCMCs (on foot) & 0.14 & 0.008 \\
\hline
\end{tabular}




\begin{tabular}{ll}
\hline Travel time form HCMCs (using a vehicle) & 0.25 \\
\hline Level of nearest service & 0.11 \\
\hline Distance from main roads & 0.18 \\
\hline Distance from green spaces & 0.13 \\
\hline Distance from public transport stations & 0.19 \\
\hline
\end{tabular}

To clarify the implementation steps, the raster maps of four criteria are illustrated in Fig. 4.
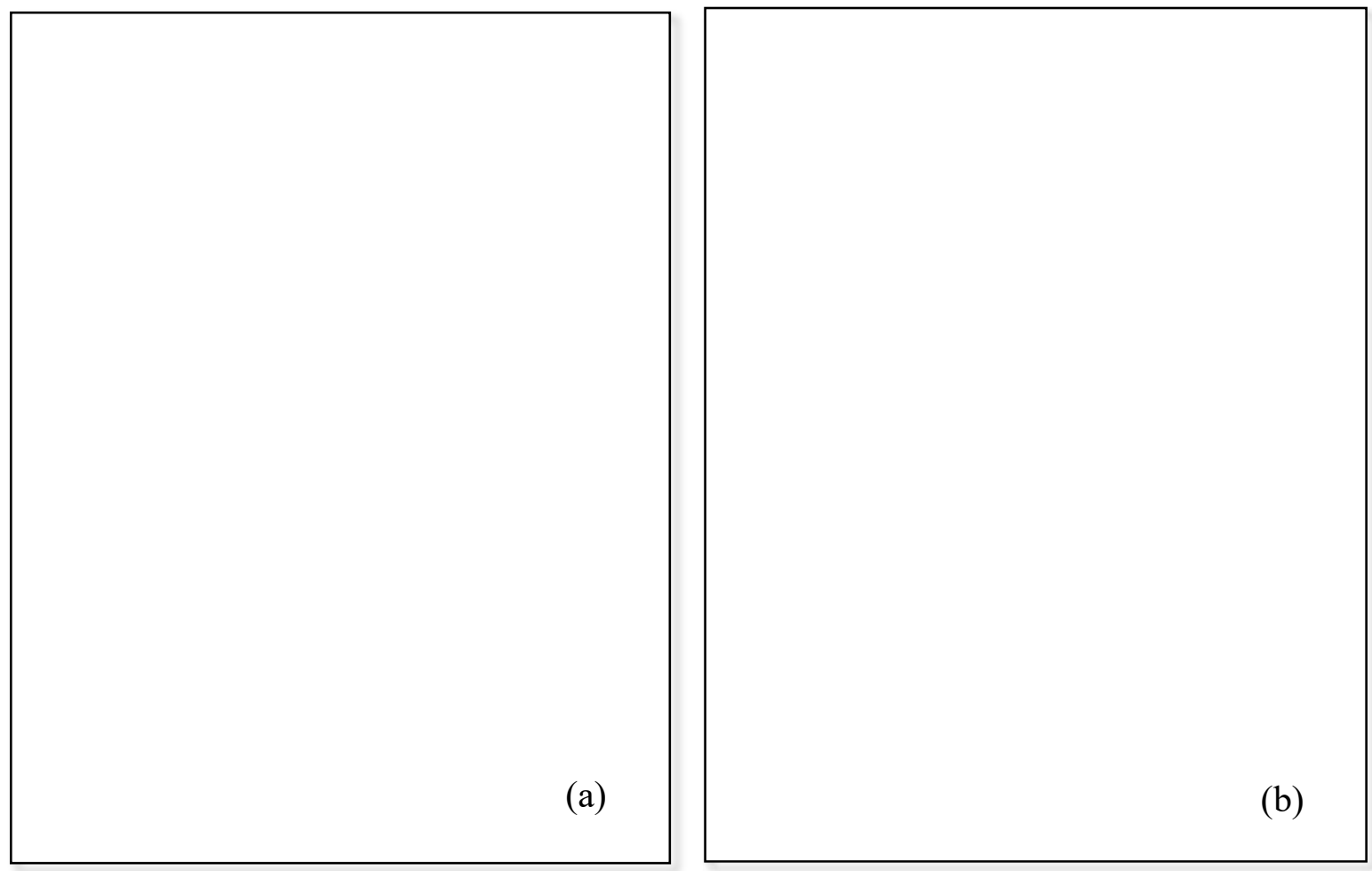

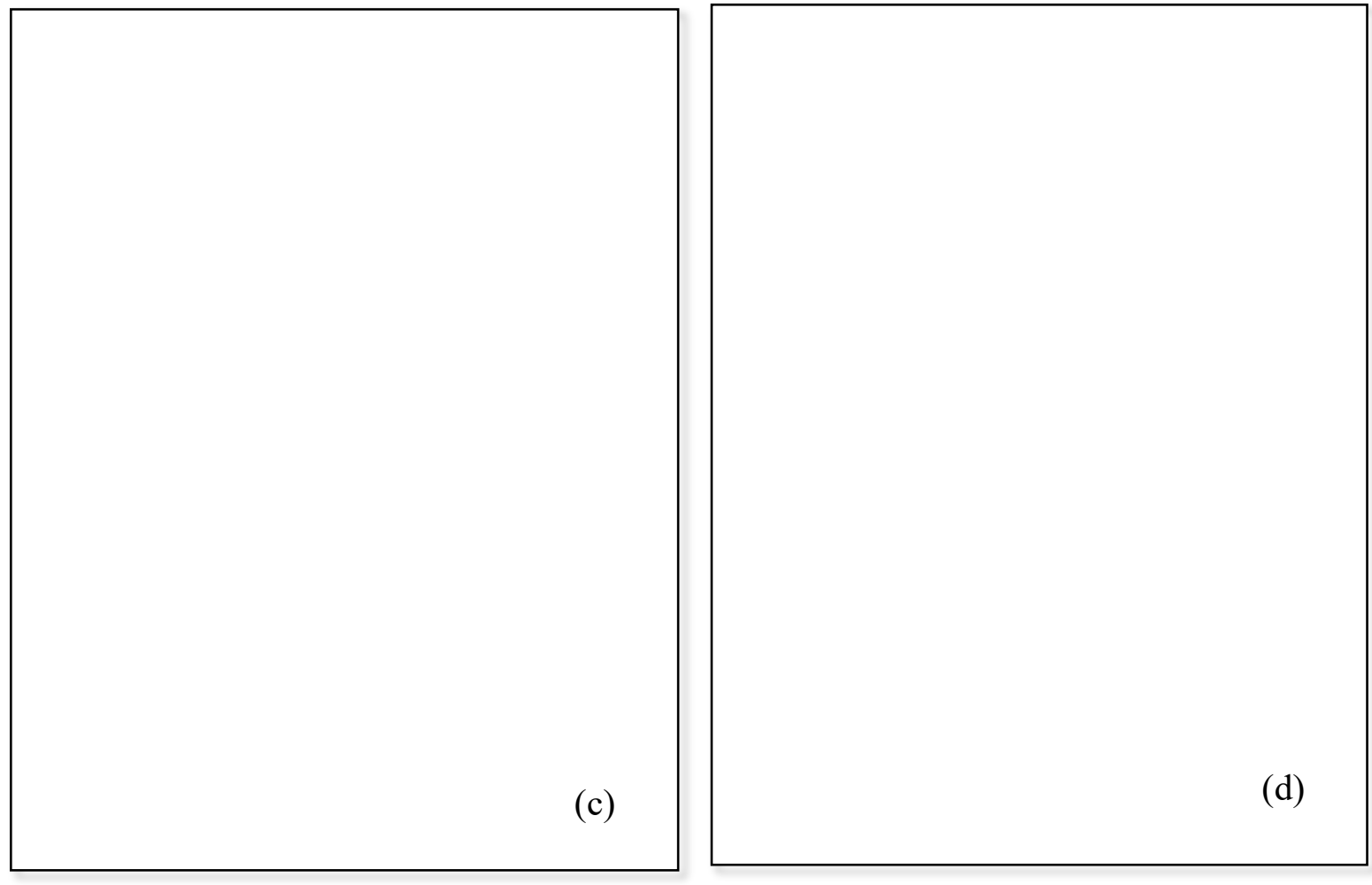

Fig. 4. Maps of the four criteria of spatial health accessibility: a) distance from HCMCs; b) distance from main roads; c) distance from parks and green spaces; d) distance from public transport stations.

\subsubsection{Creating Density and Distribution Maps of HCMCs}

Density is related to the number of HCMCs per $\mathrm{km}^{2}$. This layer is prepared using the density function as shown in Fig. 5(a). Spatial distribution is calculated based on the proportion of HCMCs in each municipal sector in a district as shown in Fig. 5(b). 

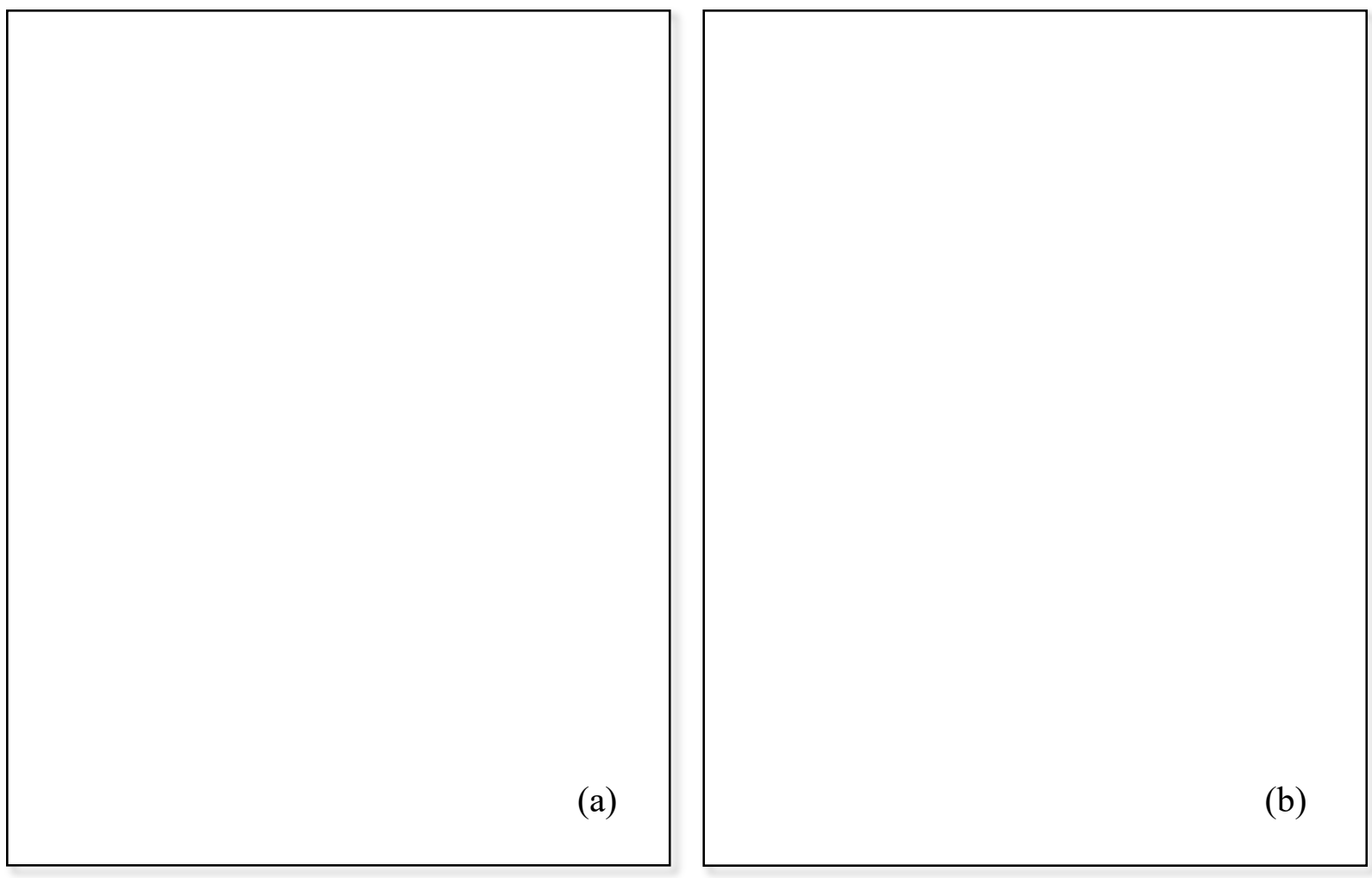

Fig. 5. Maps of: a) density of HCMCs; b) distribution of HCMCs.

\subsubsection{Generating Air Pollution Map}

The raster layer of air pollution was prepared using the Kriging interpolation method. The output raster layer is shown in Fig. 6. 


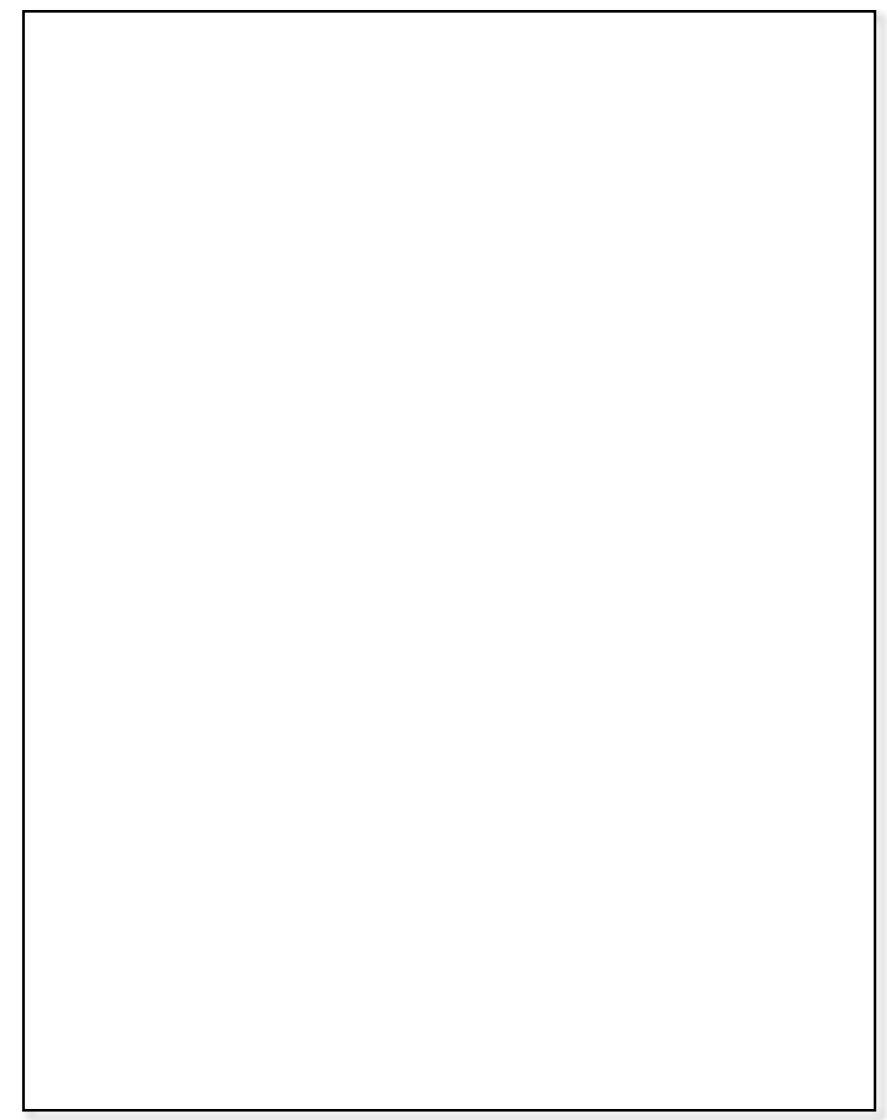

Fig. 6. Maps of air pollution in the study area (based on annual AQI).

\section{Discussions}

This paper proposed a new approach to model spatial health equity in an urban environment. First, data on the accessibility to HCMCs, green spaces and public transport stations were generated and integrated using the WLC method. The weighting process was accomplished by interviewing 50 experts in related disciplines. The results achieved demonstrated that 'travel time to HCMCs (using a vehicle)' had the highest relevance of all the criteria. After that 'distance from public transport stations' was the second most relevant criterion for spatial health accessibility. After implementing WLC, the health spatial accessibility emerged as illustrated in Fig.7. 


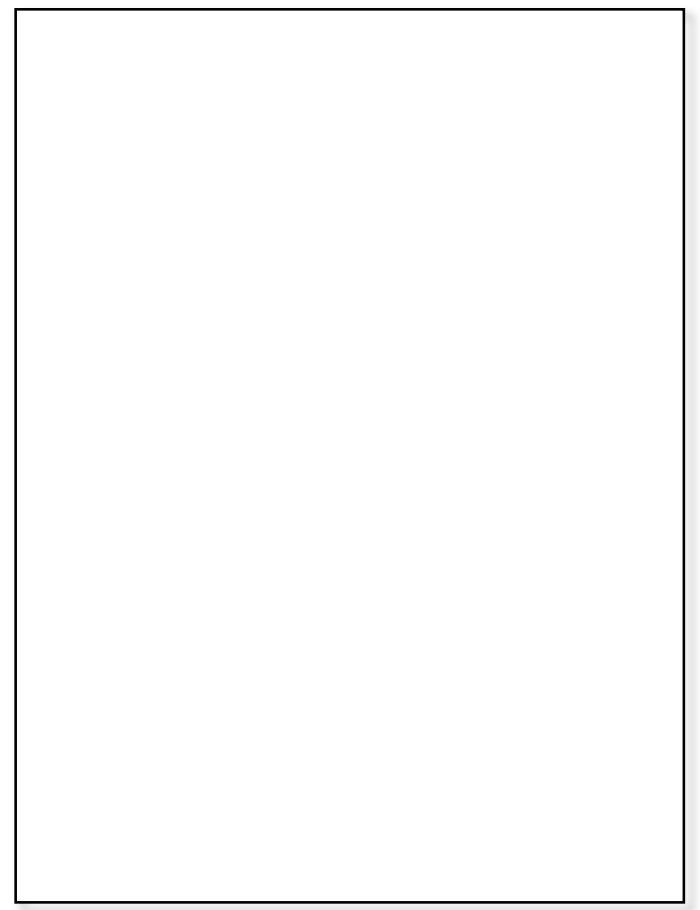

Fig. 7. Spatial health accessibility map of the study area.

To create spatial health equity, the raster map layers of spatial health accessibility, the density of HCMCs, distribution of HCMCs and air pollution level were aggregated using FIS. Some rules of the designed FIS are stated in Fig. 8.

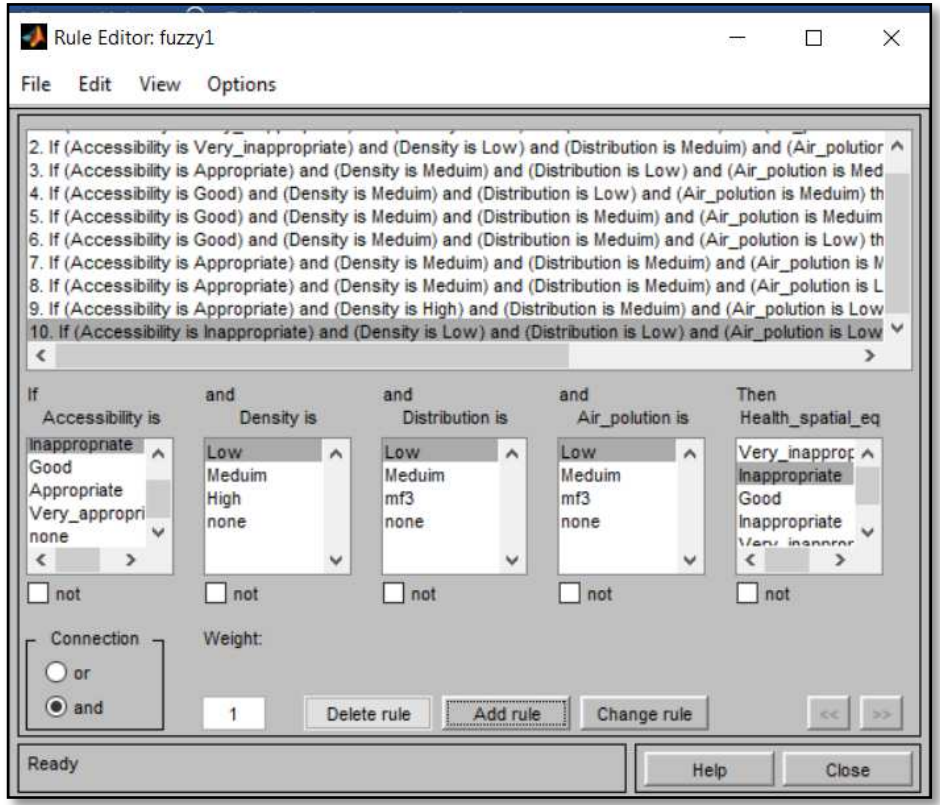


Fig. 8. Designed FIS rule-base.

According to the designed rules, the spatial health equity map could be generated. Based on the values of accessibility, density, distribution and air pollution level, the spatial equity status was inferred as depicted in Fig. 9.

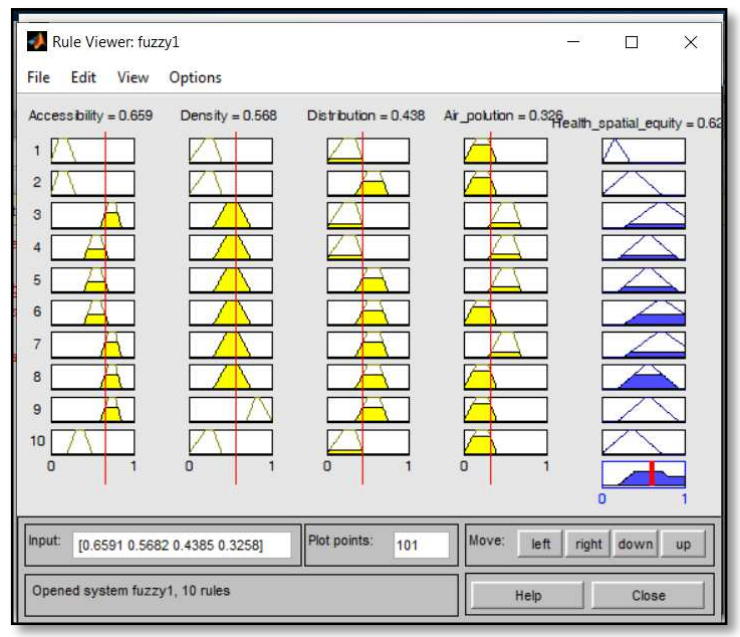

Fig. 9. Spatial health equity status inferred from the rules.

According to the rule-base and using the Mamdani inference method, the spatial health accessibility map of the study area was derived as shown in Fig. 10.

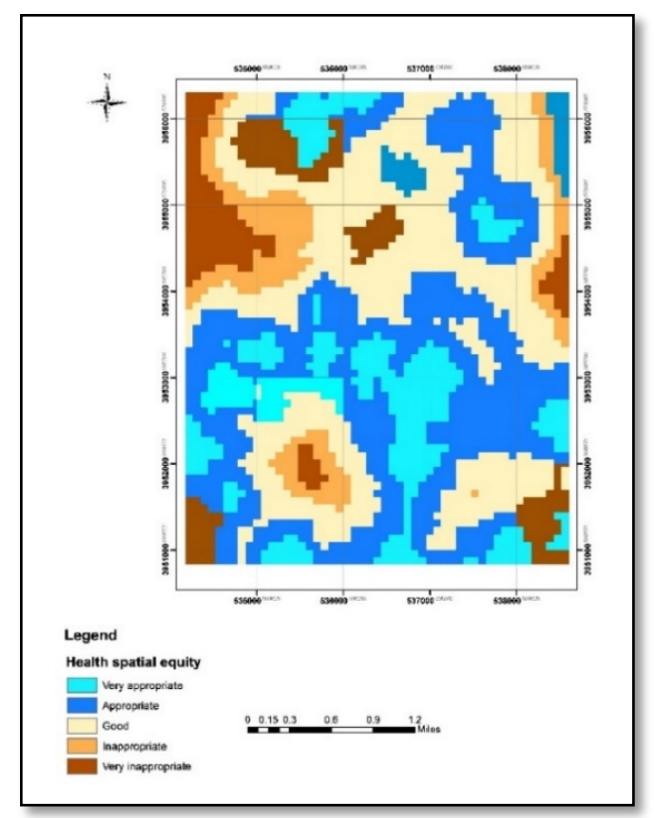

Fig. 10. Spatial health equity map of the study area. 
The proposed method was implemented in District 6 of Tehran. The compiled results show that the northwest and northeast of District 6 generally suffers from inappropriate access to HCMCs while the south part has appropriate access. According to the density and distribution of HCMCs and air pollution levels in these areas, spatial equity varies, although the health equity status is highly related to the accessibility map. Based on the reference data and therefore the FIS designed, accessibility to HCMCs, their density and distribution and air pollution levels, the spatial health equity is 'appropriate' or 'very appropriate' in almost $62 \%$ of the study area, 'good' in $20 \%$ and 'inappropriate' or 'very inappropriate' in $18 \%$ of the study area. 'Inappropriate' and 'very inappropriate' categorizations are in the northwest and northeast of the study area.

\subsection{Evaluation of the Spatial Health Equity Map}

To evaluate the achieved spatial health equity map of the study area, it was compared with a health equity map derived from citizens' opinions using VGI. The spatial health equity of each location was identified from citizens by marking the location and their providing the spatial health equity of each location. Fig. 11 shows the designed web-based GIS.

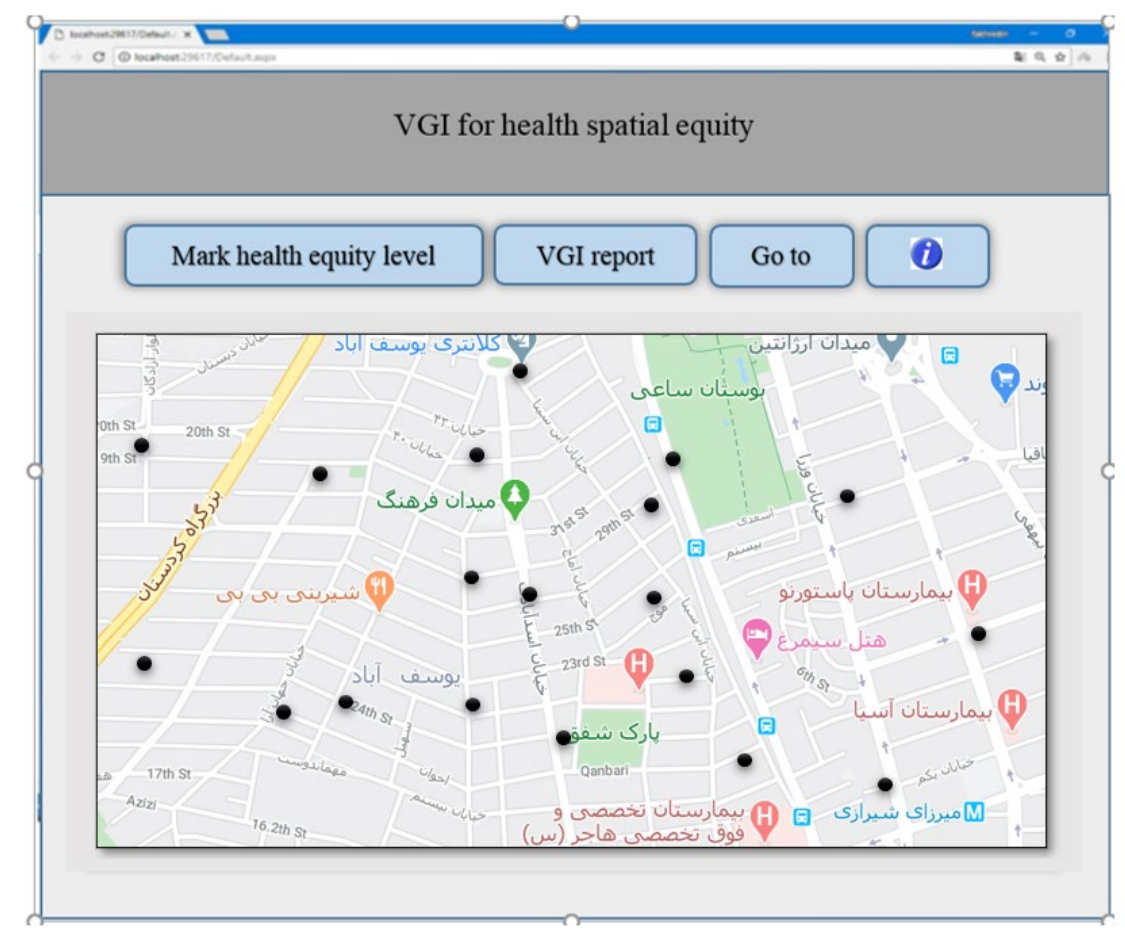

Fig. 11. Graphical user interface of the VGI collection website. 
After collecting the citizens' data, the spatial health equity map was derived by IDW interpolation. Data were categorized into five levels ( 1 to 5) corresponding to levels of spatial health equity ranging from 'very appropriate' to 'very inappropriate'. A total of 96 citizens from the study area entered information as shown in Fig. 12(a). The characteristics of the participants are described in Table 4. Interpolation of the collected VGI from the study area produced the participatory spatial health equity map as shown in Fig. 12(b).

(a)

(b)

Fig. 12. VGI collected from citizens i the study area: a) point data of VGI about the spatial health equity status; b) spatial health equity map derived by interpolating VGI.

Table 4

Summary of participant characteristics.

\begin{tabular}{|c|c|c|c|c|c|c|c|}
\hline \multicolumn{2}{|c|}{ Gender } & \multicolumn{3}{c|}{ Age (years) } & \multicolumn{3}{c|}{ Education } \\
\hline Male & Female & $15-40$ & $40-70$ & Over 70 & High school & Diploma to Bachelor & Master-Doctoral \\
\hline 45 & 34 & 12 & 51 & 16 & 4 & 38 & 37 \\
\hline
\end{tabular}

Assessment of the map resulting from VGI shows some differences between the spatial health equity status. Our findings confirmed that based on accessibility to HCMCs, their density and 
distribution and air pollution levels, the spatial health equity is 'appropriate' or 'very appropriate' in almost $62 \%$ of the study area, 'good' in $20 \%$ and 'inappropriate' or 'very inappropriate' in $18 \%$ of the study area. 'Inappropriate' and 'very inappropriate' categorizations are in the northwest and northeast of the study area.

The collected VGI from the citizens showed $72 \%$ compatibility with these findings. Fig. 13 shows the differences between the spatial health equity status using reference data and VGI. The compatibility is calculated using ' 100 -summation of differences between the same classes'.

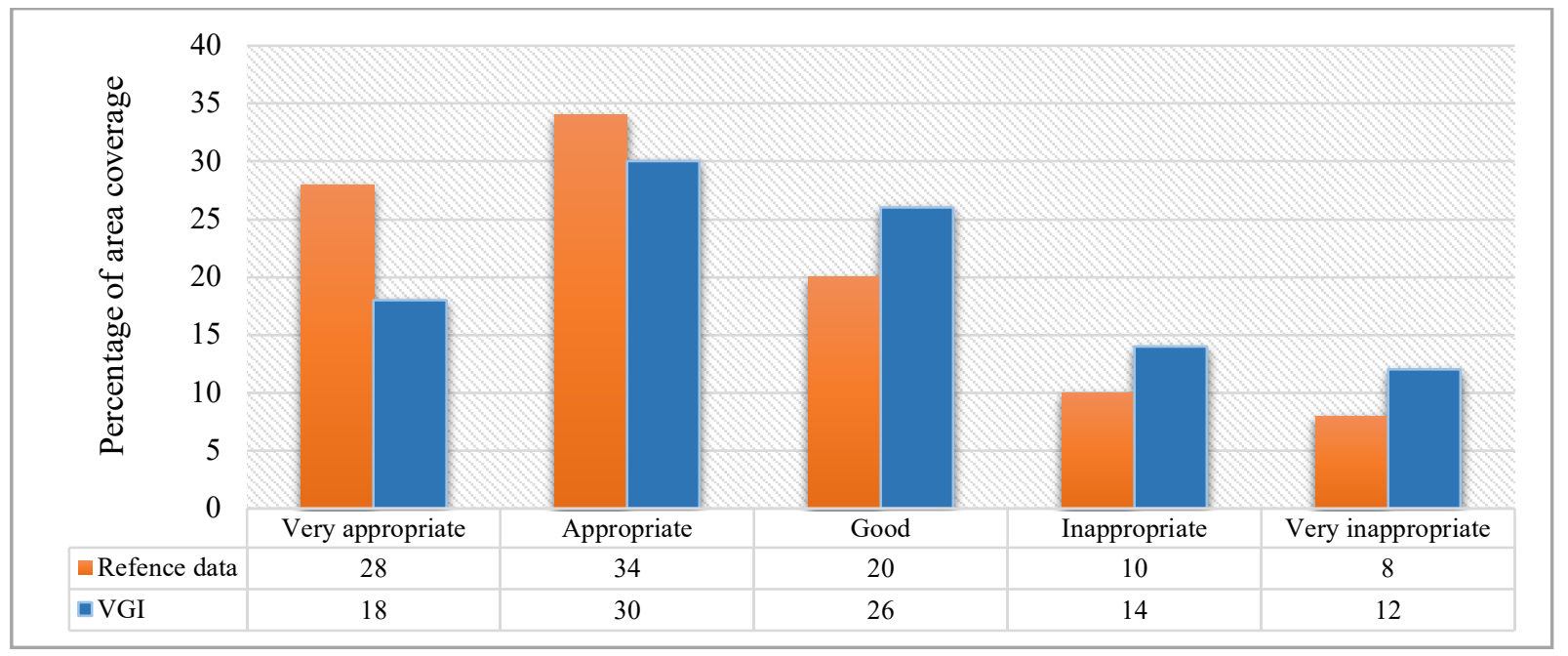

Fig. 13. Comparison between the reference data and VGI.

The other fundamental measures to compare the accuracy of the archived results are 'precision', 'recall' and F-score (Raghavan et al., 1989). Precision, denotes to the degree of accuracy of the specified classes; it is computed by Eq. 17:

$$
\text { Precision }=\frac{T P}{T P+F P}
$$

where TP is true positive cells, which are cells of the same class in the reference data, FP is false positive cells that vary in class (They have the same location but the level of spatial health equity is a different location).

Recall is the ratio between true positive cells and true negative (TN) cells that have been mistakenly classified using VGI, as depicted in Eq.18.

$$
\text { Recall }=\frac{T P}{T P+T N}
$$


According to the precision and recall, the F-score can be computed as Eq. 19:

$$
F-\text { score }=2 \times \frac{\text { Precision }+ \text { Recall }}{\text { Precision }+ \text { Recall }}
$$

To compare the achieved results of the reference data with FIS and VGI, the precision, recall and F-scores were calculated for each class of the spatial health equity maps. The higher the value of the F-score, the more accurately the class is estimated.

Table 5

Accuracy assessment of the VGI spatial equity map.

\begin{tabular}{lccc}
\hline Spatial health equity level & Precision & Recall & F-score \\
\hline Very appropriate & 0.73 & 0.87 & 0.79 \\
\hline Appropriate & 0.89 & 0.86 & 0.87 \\
\hline Good & 0.76 & 0.74 & 0.75 \\
\hline Inappropriate & 0.71 & 0.78 & 0.73 \\
\hline Very inappropriate & 0.67 & 0.69 & 0.68 \\
\hline
\end{tabular}

As seen in Table 5, the highest accuracy is for the 'appropriate' level of spatial health equity and the lowest accuracy is related to the 'very inappropriate' level. It can therefore be deducted that the 'appropriate' region is classified more accurately than the other regions, especially with respect to the 'very inappropriate' class. It should be noted that the 'appropriate' class is located in the southern half of the study area.

\section{Conclusion}

In this study, a new approach for modelling spatial health equity in an urban area has been proposed and evaluated. First, the spatial health accessibility map was created based on a weighted linear combination method. Six criteria were defined based on expert knowledge, related research and AHP. The weighting process was completed by 50 experts. Spatial raster layers were then combined. Second, the raster layers of spatial health accessibility, the density of HCMCs, the distribution of HCMCs and air pollution levels were aggregated using FIS. The results show that the southern part of the study area has higher health equity than the northern part. Further, the 
north-western part of the study area has inferior health equity compared to the other parts of the study area.

To evaluate the achieved spatial health accessibility map of the study area, it was compared with the health equity status of citizens, derived from interpolating VGI using IDW. The health status

of each location gathered from citizens' opinions was input to a web-based GIS. The health equity status was categorized into five levels from 'very appropriate' to 'very inappropriate' (1 to 5). A total of 96 citizens from the study area entered information. According to the precision, recall and F-score measures, the 'appropriate' level of spatial health equity was the most accurate and the 'very inappropriate' level had the lowest accuracy. It can therefore be deducted that the 'appropriate' region was classified more accurately, which mapped to the southern half of the study area.

For future research, further parameters could be applied such as traffic data, population density and age to model spatial health equity of urban areas. Improving the algorithm on the other public participation open-source platforms for gathering VGI such as OpenStreetMap (OSM) is also recommended.

\section{References}

Alzouby, A.M., Nusair A.A., Taha L.M., 2019. GIS based Multi Criteria Decision Analysis for analyzing accessibility of the disabled in the Greater Irbid Municipality Area, Irbid, Jordan, Alexandria Engineering Journal (58)( 2), 689-698.

Ashik, F.R., Mim, S.A., Neema, M.N., 2019. Towards vertical spatial equity of urban facilities: An integration of spatial and aspatial accessibility. Journal of Urban Management, 9 (1), 7792. 
Banerjee, A., Duflo, E., 2011. Poor Economics: A Radical Rethinking of The Way to Fight Global Poverty.

Cole, H., Triguero-Mas, M., Connolly, J., Anguelovski, I., 2019. Determining the health benefits of green space: Does gentrification matter? Health \& Place, (57), 1-11.

Corburn, J., Cohen, A., 2012. Why We Need Urban Health Equity Indicators: Integrating Science, Policy, and Community. PLoS medicine, 9, e1001285.

Dell’Ovo, M., Capolongo, S., Oppio, A., 2018. Combining spatial analysis with MCDA for the siting of healthcare facilities, Land Use Policy (76), 634-644.

Tayyari Dehbarez, N., 2018. Hospital choice in times of restructuring the hospital sector. PhD dissertation. Department of Public Health, Aarhus University.

Fan, P., Xu, L., Chen, J., 2017. Accessibility of public urban green space in an urban periphery: The case of Shanghai. Landscape and Urban Planning, (165), 177-192.

Giuliano, G., Kang, S., 2018. Spatial dynamics of the logistics industry: Evidence from California. Journal of Transport Geography, 66(1), 248-258. https://doi.org/ 10.1016/j.jtrangeo.2017.11.013.

Goodchild, Mi., Li, L., 2012. Assuring the Quality of Volunteered Geographic Information. Spatial Statistics. 1. 110-120. 10.1016/j.spasta.2012.03.002.

Habibi, R., Alesheikh, A., Mohammadinia, A., Sharif, M., 2017. an assessment of spatial pattern characterization of air pollution: a case study of CO and PM2.5 in Tehran, Iran. International Journal of Geo-Information, 6(6), 270. 
Hunter R.F., Cleary A., Braubach M., 2019. Environmental, Health and Equity Effects of Urban Green Space Interventions. In: Marselle M., Stadler J., Korn H., Irvine K., Bonn A. (eds) Biodiversity and Health in the Face of Climate Change. Springer, Cham.

Helbich, M., 2018. Toward dynamic urban environmental exposure assessments in mental health research. Environmental research, (161), 129-135, doi.org/10.1016/j.envres.2017.1.006.

Hartig, T., Mitchell, R., Vries, S., Frumkin, H., 2014. Nature and health. Annual Review of Public Health, (35), 207-228. DOI: 10.1146/annurev-publhealth-032013-182443.

Harris, R.B., Cormack, D., Stanley, J., 2013. The relationship between socially-assigned ethnicity, health and experience of racial discrimination for Māori: Analysis of the 2006/07 New Zealand Health Survey. BMC public health 13(1),844. 10.1186/1471-2458-13-844.

Joseph, A.E., Bantock, P.R., 1982. Measuring potential physical accessibility to general practitioners in rural areas: A method and case study. Social Science \& Medicine, 16(1), 8590. https://doi.org/10.1016/0277-9536(82)90428-2.

Koenig, J. G., 1980. Indicators of urban accessibility: Theory and application. Transportation, 9, 145-172.

Kolak, M., Steptoe, M., Manprisio, H., Azu-Popow, L., Hinchy, M., Malana, G. \& Maciejewski, R., 2020. Extending Volunteered Geographic Information(VGI) with geospatial software as a service: participatory asset mapping infrastructures for urban health. 10.1007/978-3-030-19573-1_11.

Kurata, M., Takahashi, K., Hibiki A., 2020. Gender differences in associations of household and ambient air pollution with child health: Evidence from household and satellite-based data in Bangladesh. World Development (128), 104779. 
Lee, J., Miller, H. J., 2019. Analyzing collective accessibility using average space-time prisms. Transportation Research Part D: Transport and Environment, 69(4), 250-264. https://doi.org/10.1016/j.trd.2019.02.004.

Lee, C.C., 1990. Fuzzy logic in control systems: fuzzy logic controller-Part I. IEEE Trans. Syst Man Cybern, 20(2), 404-418.

Levere, M., Orzol, S., Leininger, L., Early, N., 2019. Contemporaneous and long-term effects of children's public health insurance expansions on Supplemental Security Income participation. Journal of Health Economics (64), 80-92.

Lättman, K., Olsson, L. E., Friman, M., 2018. A new approach to accessibility: Examining perceived accessibility in contrast to objectively measured accessibility in daily travel. Research in Transportation Economics, 69(6), 501-511. https://doi.org/ 10.1016/j.retrec.2018.06.002.

Liu, Sh., Qin, Y., Xu, Y., 2019. Inequality and influencing factors of spatial accessibility of medical facilities in rural areas of china: a case study of Henan province. International Journal of Environmental Research and Public Health, 16 (10), 1833. 10.3390/ijerph16101833.

Lu, Ch., Zhang, Z., Lan, X., 2019. Impact of China's referral reform on the equity and spatial accessibility of healthcare resources: A case study of Beijing. Social Science \& Medicine, (235), 112386.

Lotfi-Zadeh, A., 1965. Fuzzy sets. Information and Control. 8 (3), 338353. doi:10.1016/S0019-9958(65)90241-X.

Malczewski, J., 2011. Local weighted linear combination. Transaction in GIS, (15), 439-455. 10.1111/j.1467-9671.2011.01275. x. 
Malczewski, J., 2000. On the Use of Weighted Linear Combination Method in GIS: Common and Best Practice Approaches. T. GIS. 4. 5-22. 10.1111/1467-9671.00035.

Mamdani, E.H., 1977. Application of Fuzzy Logic to Approximate Reasoning Using Linguistic Synthesis, IEEE Trans. Comput. C-26 1182-1191.

Mansour, Sh., 2016. Spatial analysis of public health facilities in Riyadh Governorate, Saudi Arabia: a GIS-based study to assess geographic variations of service provision and accessibility. Geo-spatial Information Science, (19), 26-38. 10.1080/10095020.2016.1151205.

McLafferty, S., Schneider, D. \& Abeltc, K. (2020) Placing volunteered geographic health information: Socio-spatial bias in 311 bed bug report data for New York City. Health \& Place (62), 102282.

Mishra, S., Sahu, P., Sarkar, A., Mehran, B., Sharma, S., 2019. Geo-spatial site suitability analysis for development of health care units in rural India: Effects on habitation accessibility, facility utilization and zonal equity in facility distribution. Journal of Transport Geography, (78), 135-149. 10.1016/j.jtrangeo.2019.05.017.

Mooney, P., Corcoran, P., Ciepluch, B., 2013. The potential for using volunteered geographic information in pervasive health computing applications. Journal of Ambient Intelligence and Humanized Computing, (4),731-745.

Moore, L., Diez R.A., Evenson, K., McGinn, A., Brines, Sh., 2008. Availability of recreational resources in minority and low socioeconomic status areas. American journal of preventive medicine, (34), 16-22. 10.1016/j.amepre.2007.09.021.

Myers, D. E., 1994. Spatial interpolation: an overview. Geoderma. Volume 62, Issues 1-3, 15 March 1994, Pages 17-28.https://doi.org/10.1016/0016-7061(94)90025-6. 
Neisani Samani, Z., Karimi, M., Alesheikh, A., 2020 .Environmental and infrastructural effects on respiratory disease exacerbation: a LBSN and ANN-based spatio-temporal modelling. Environ Monit Assess (192), 90. doi:10.1007/s10661-019-7987-x.

Neisani Samani, Z., Alesheikh, A. A., 2019. uncertainty modelling of citizen-centered group decision making using fuzzy-vikor case study: site selection of healthcare services. Int. Arch. Photogramm. Remote Sens. Spatial Inf. Sci., XLII-4/W(18), 809-814, https://doi.org/10.5194/isprs-archives-XLII-4-W18-809-2019.

Neisani, Z., Torabi Azad, M., Neysani Samani, N., 2014. Design and Implementation of a User-Centered Tourism Guide System based on Weather Conditions Preferences.

Ni, J., Qian, T., Xi, Ch., Rui, Y., Wang, J., 2016. Spatial Distribution Characteristics of Healthcare Facilities in Nanjing: Network Point Pattern Analysis and Correlation Analysis, Int. J. Environ. Res. Public Health, 13(8), 833; doi:10.3390/ijerph13080833.

Pierangeli, M.J., Nieuwenhuijsen, Cirach M., Rojas-Rueda D., 2020. Health equity and burden of childhood asthma - related to air pollution in Barcelona. Environmental Research, 109067.

Powell, L., Slater, S., Chaloupka, F., Harper, D., 2006. Availability of physical activity-related facilities and neighborhood demographic and socioeconomic characteristics: a national study. American journal of public health, (96), 1676-80. 10.2105/AJPH.2005.065573.

Ramzia, A.I., El-Bedawi M.A.L., 2019. Towards integration of remote sensing and GIS to manage primary health care centers, Applied Computing and Informatic (15),109-113.

Raghavan, V., Jung, G., Bollmann, P., 1989. A Critical Investigation of Recall and Precision as Measures of Retrieval System Performance.. ACM Transactions on Information Systems. 7. 205-229. 10.1145/65943.65945. 
Richardson, A., Boone-Heinonen, J., Popkin, B., Gordon-Larsen, P., 2012. Are neighborhood food resources distributed inequitably by income and race in the USA? Epidemiological findings across the urban spectrum. BMJ open. 2. e000698. 10.1136/bmjopen-2011-000698.

Saaty, T.L., 1980. The Analytic Hierarchy Process, Planning, Priority Setting, Resource Allocation. McGraw-Hill, New York, 1980.

Saaty, T.L., Vargas, L.G., 1991. Prediction, Projection and Forecasting. ISBN 978-94-0157954-4.

Saaty, T. L., 2005. Theory and applications of the analytic network process: Decision making with benefits, opportunities, costs, and risks. Pittsburgh: RWS Publications.

Saaty, T. L., 2008. Decision Making for Leaders: The Analytic Hierarchy Process for Decisions in a Complex World. Pittsburgh, Pennsylvania: RWS Publications. ISBN 978-09620317-8-6.

Shaoyao, Zh., Song, X., Wei, Y., Deng, W., 2019. Spatial equity of multilevel healthcare in the metropolis of chengdu, china: a new assessment approach. International Journal of Environmental Research and Public Health, (16), 493. 10.3390/ijerph16030493.

Shin, K., Lee, T., 2018. Improving the measurement of the Korean emergency medical System's spatial accessibility. Applied Geography, 100(11), 30-38. https://oi.org/ 10.1016/j.apgeog.2018.08.009.

Tobias, M., Silva, N., Rodrigues, D., 2015. Perception of health and accessibility in Amazonia: An approach with GIS mapping to making decision on hospital location. Journal of Transport \& Health, 2(2), S60-S61. https://doi.org/10.1016/j. jth.2015.04.595. 
Todd, A., Copeland, A., Husband, A., Kasim, A., Bambra, C., 2015. Access all areas? An arealevel analysis of accessibility to general practice and community pharmacy services in England by urbanity and social deprivation. BMJ Open. 2015. e007328. 10.1136/bmjopen-2014007328.

Wang, L., 2018. Unequal spatial accessibility of integration-promoting resources and immigrant health: A mixed-methods approach. Applied Geography, 92(3), 140-149. https://doi.org/10.1016/j.apgeog.2018.01.017.

Webster, R., Oliver, M., 2007. Geostatistics for Environmental Scientists: Second Edition. $10.1002 / 9780470517277$.

Whitehead, J., Pearson, A., Lawrenson, R., Atatoa-Carr, P., 2019. Spatial equity and realized access to healthcare - a geospatial analysis of general practitioner enrolments in Waikato. New Zealand. Rural and Remote Health, (19) (4):5349, 10.22605/RRH5349.

Zhang, D., Lee, I., 2014. Interpolation of Sensory Data in the Presence of Obstacles. Procedia Computer Science. 29. 2496-2506. 10.1016/j.procs.2014.05.233.

Zhong, X., Kealy, A., Duckham, M., 2016. Stream Kriging: Incremental and recursive ordinary Kriging over spatiotemporal data streams. Computers \& Geosciences. 90, Part A. 134 - 143. 10.1016/j.cageo.2016.03.004. 


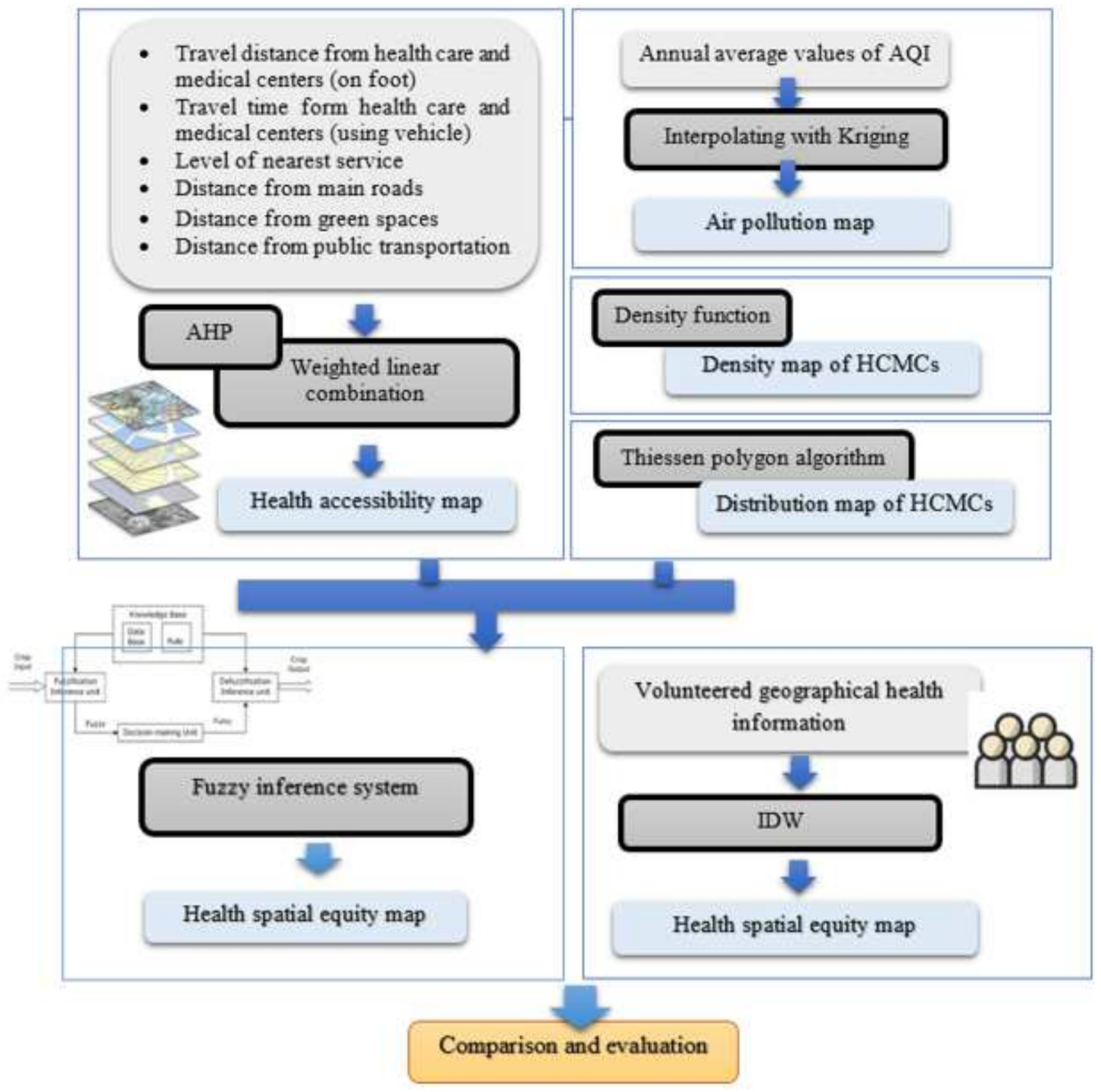

Figure 1

Flowchart of the methodology. 


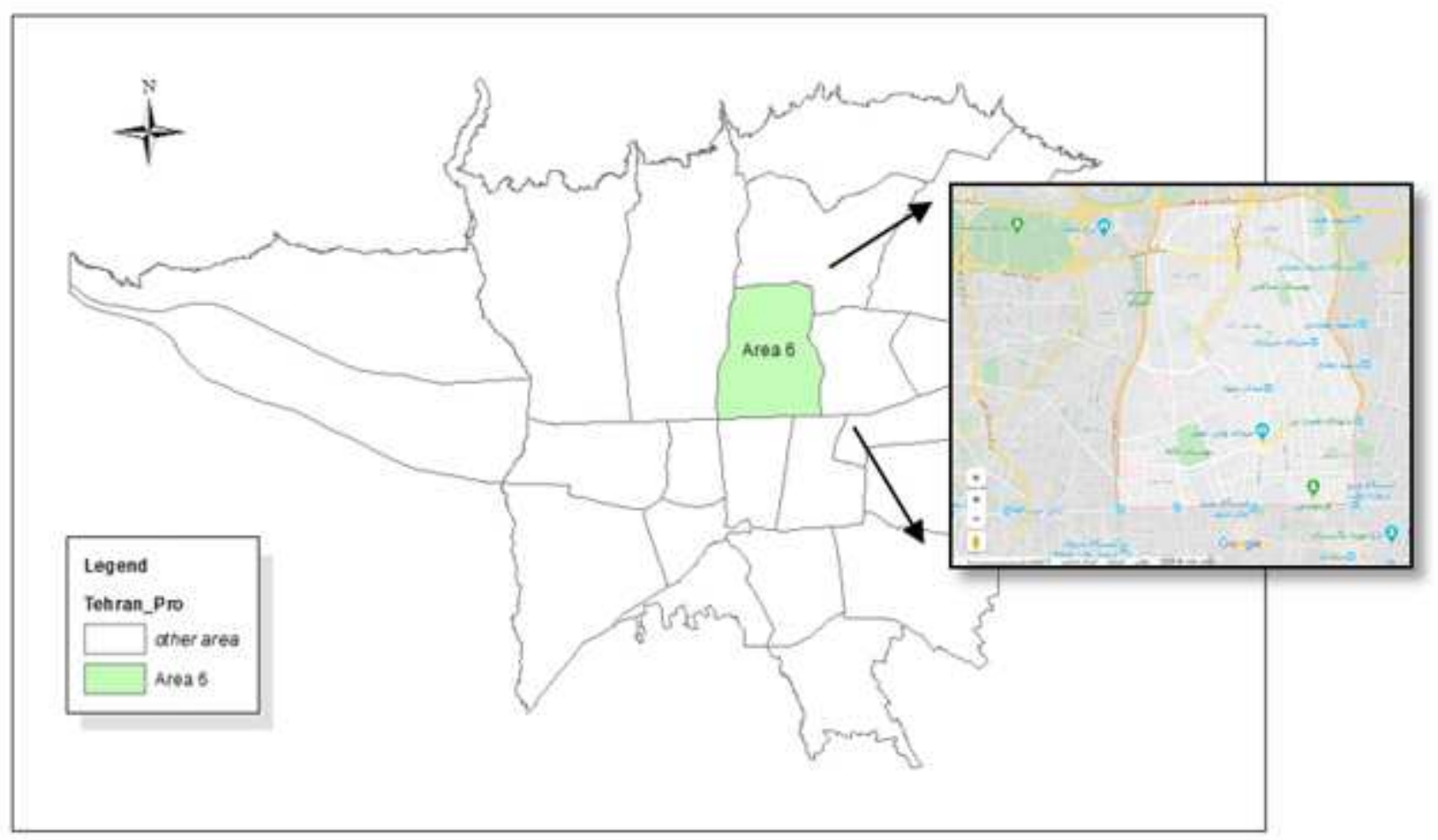

Figure 2

The study area (District 6 of Tehran).

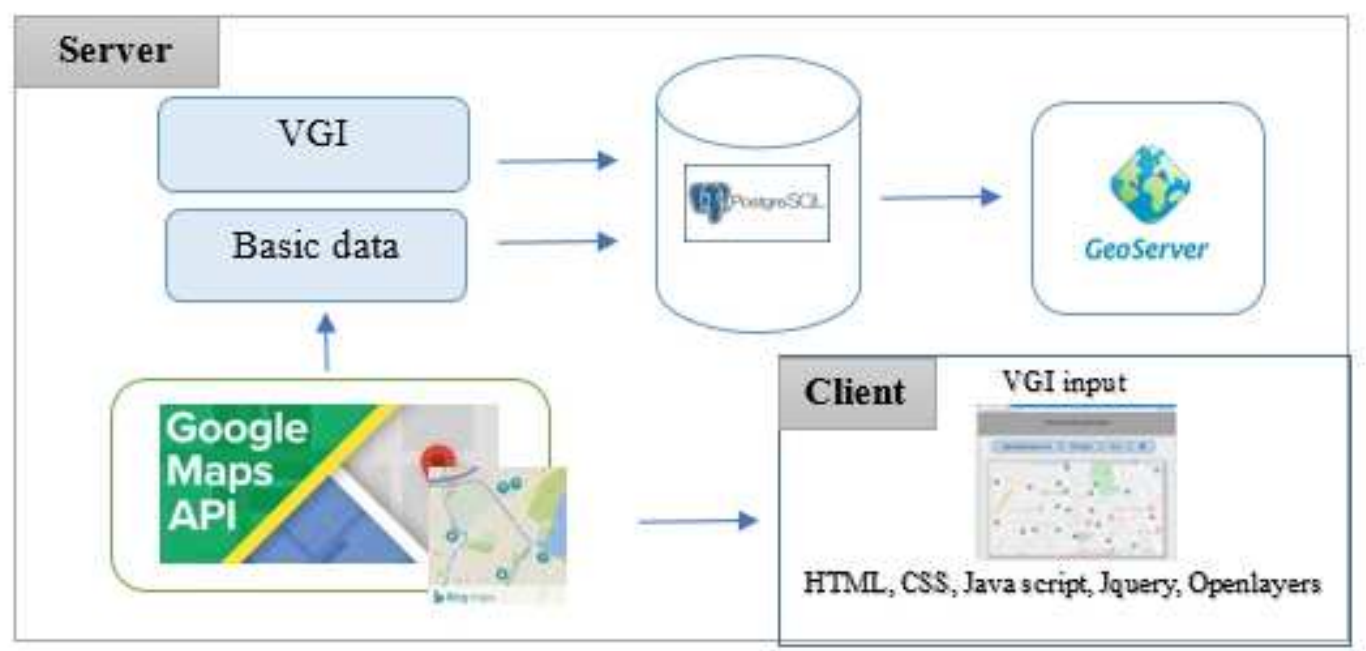

Figure 3

The architecture of VGI system. 

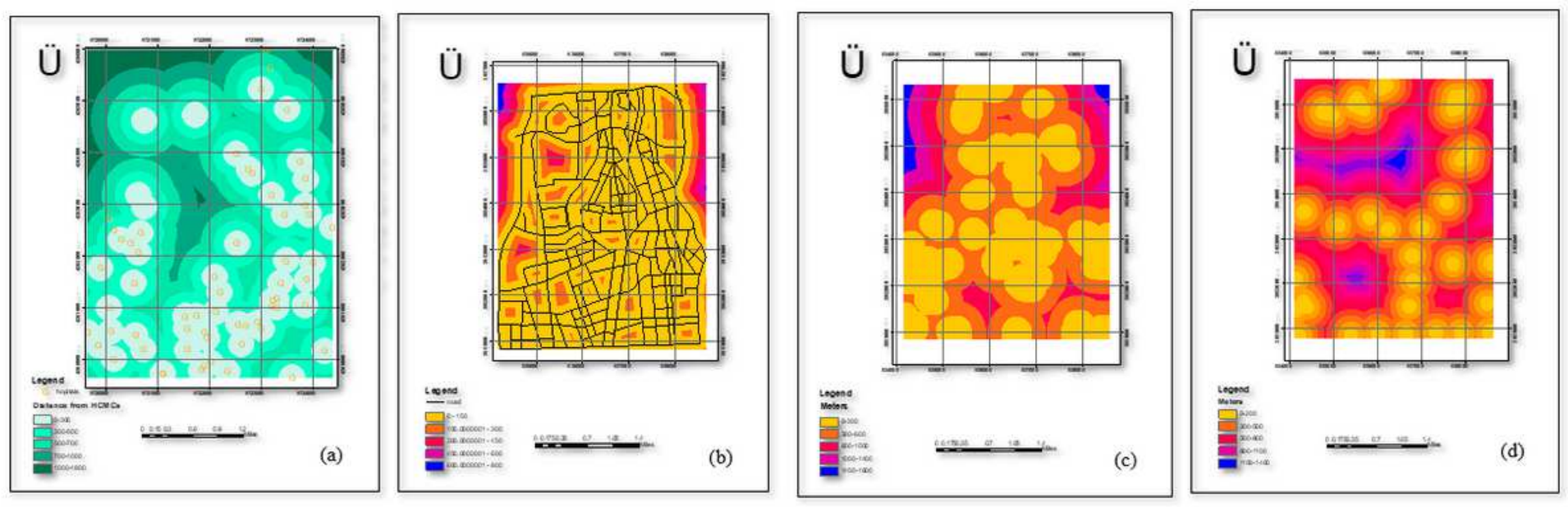

Figure 4

Maps of the four criteria of spatial health accessibility: a) distance from HCMCs; b) distance from main roads; c) distance from parks and green spaces; d) distance from public transport stations.
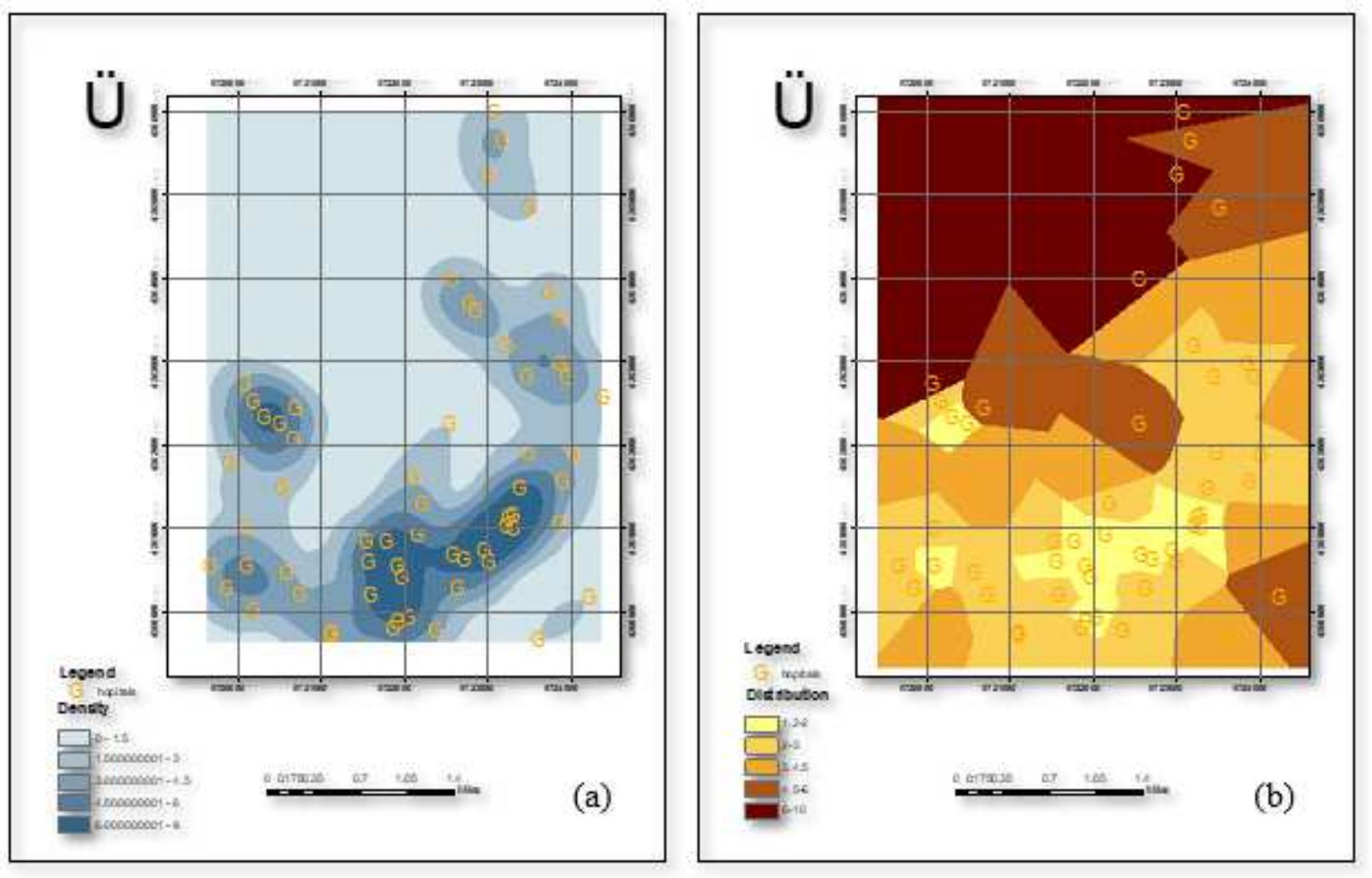

Figure 5

Maps of: a) density of HCMCs; b) distribution of HCMCs. 


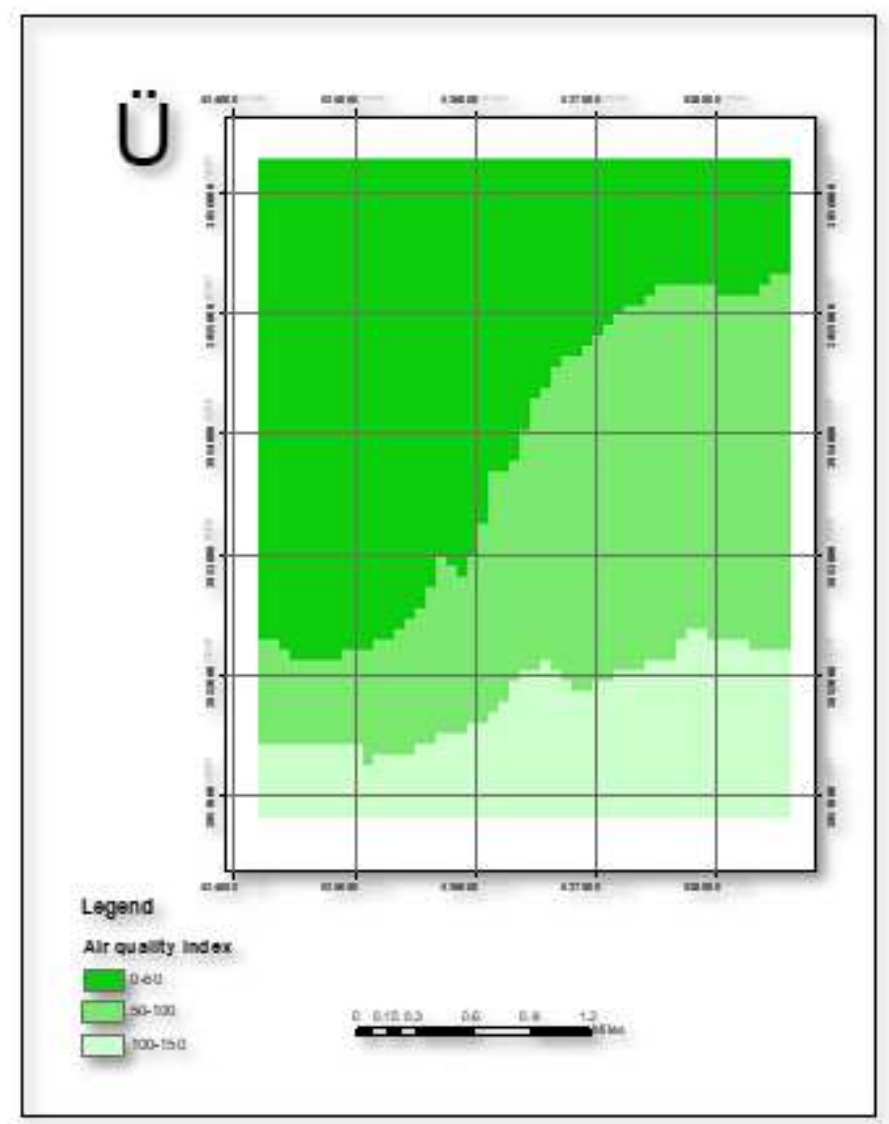

Figure 6

Maps of air pollution in the study area (based on annual AQI).

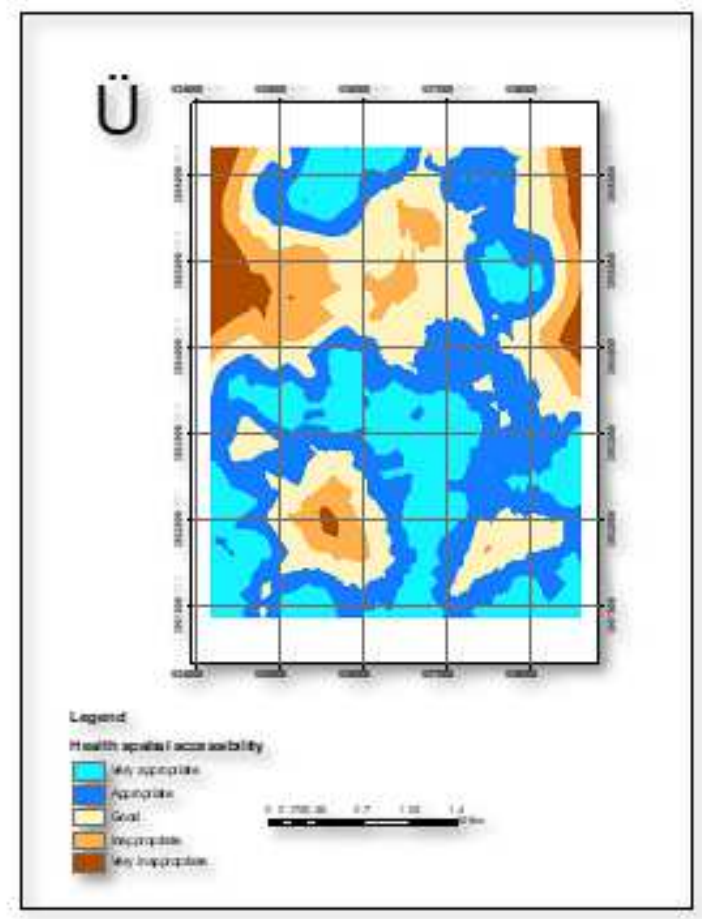


Figure 7

Spatial health accessibility map of the study area.

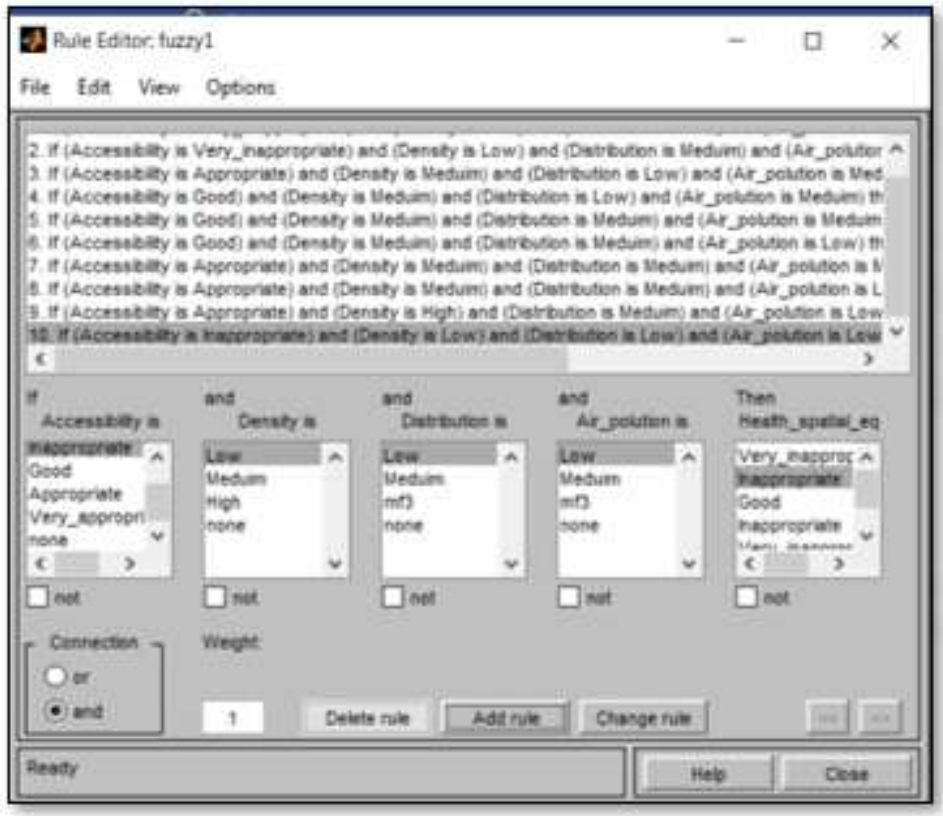

Figure 8

Designed FIS rule-base.

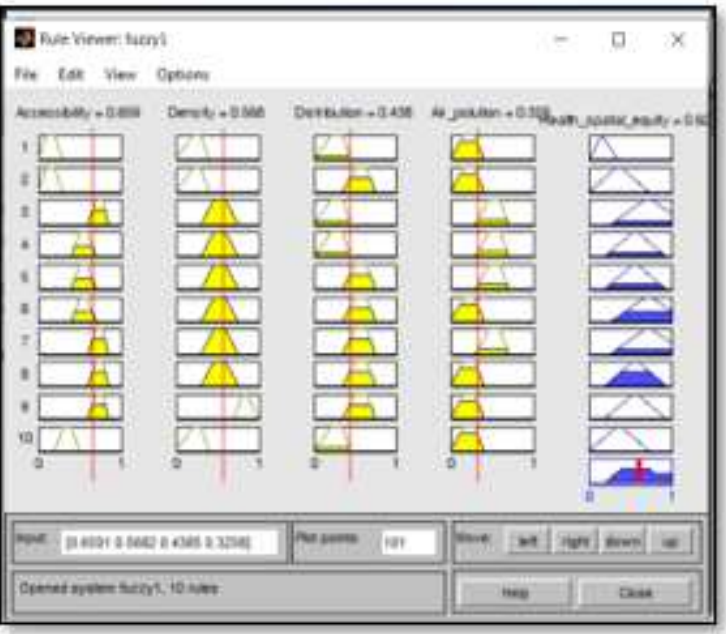

Figure 9

Spatial health equity status inferred from the rules. 


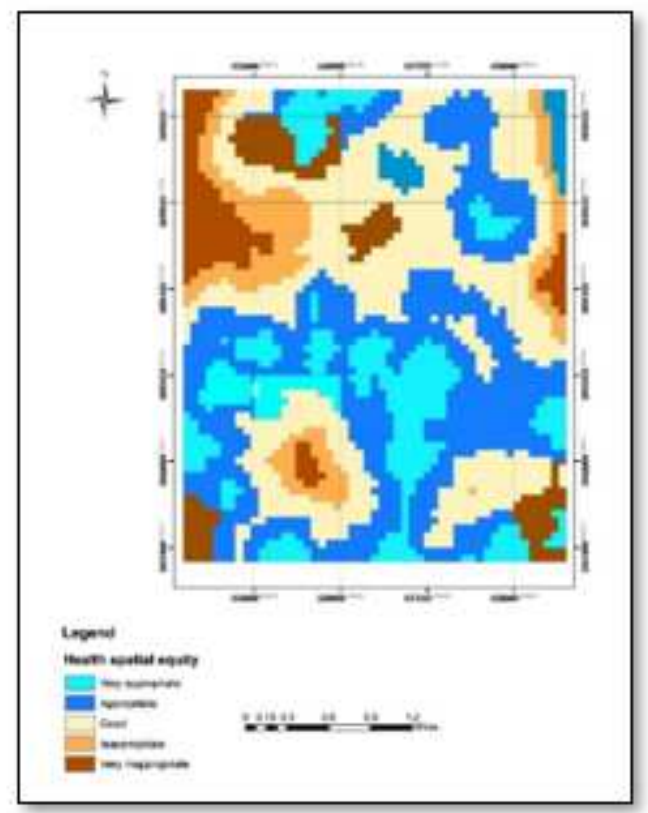

Figure 10

Spatial health equity map of the study area.

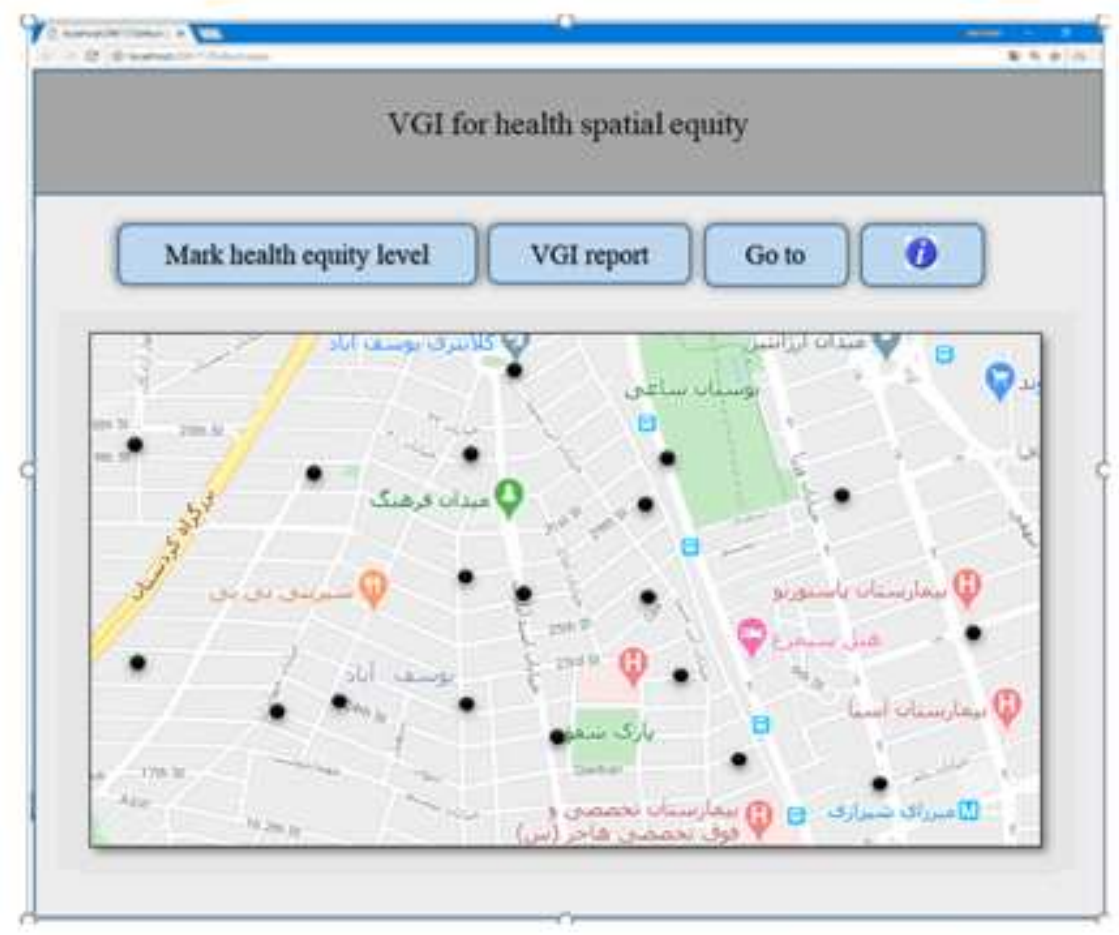

Figure 11

Graphical user interface of the VGI collection website. 

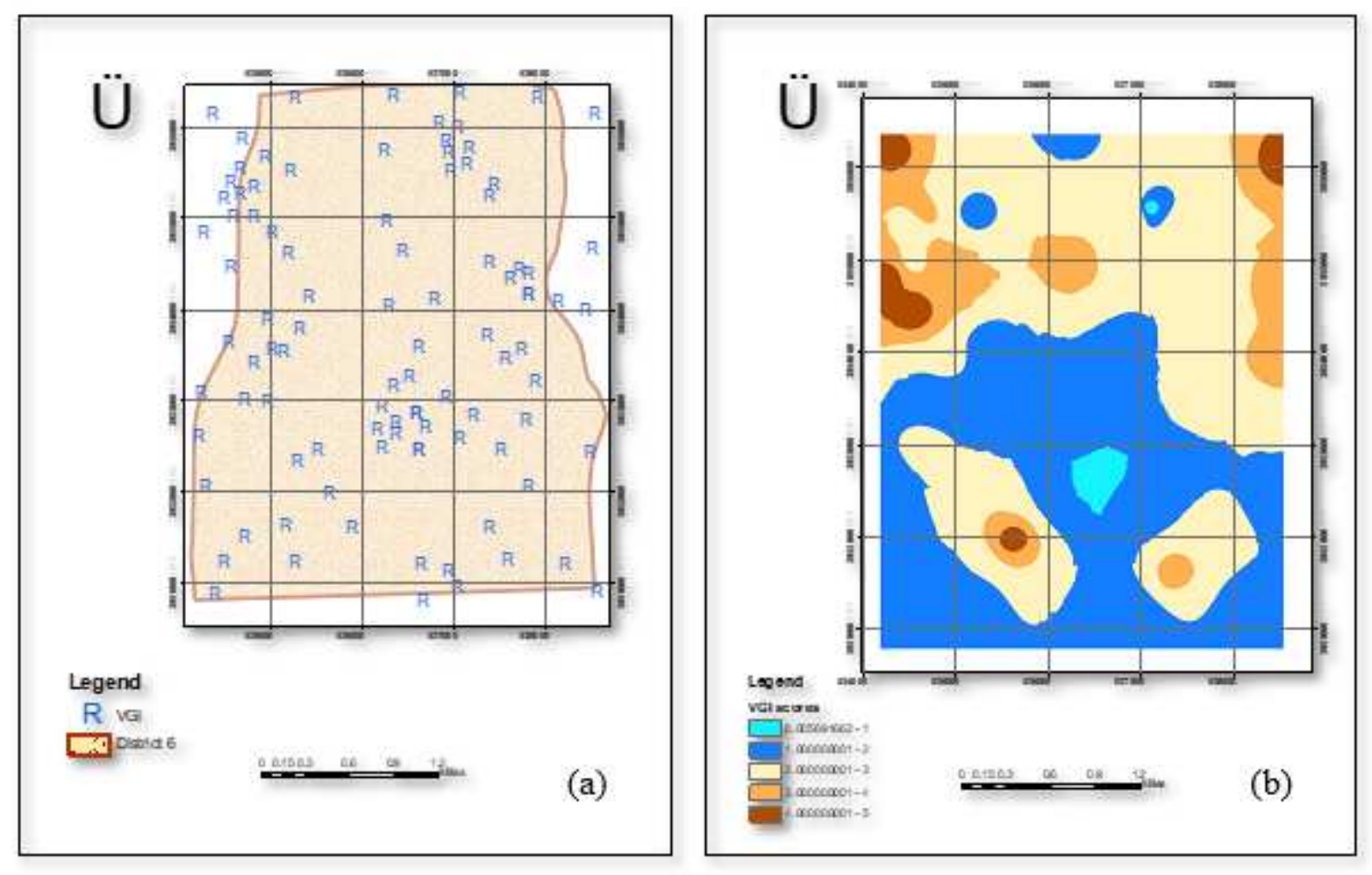

Figure 12

VGI collected from citizens i the study area: a) point data of VGI about the spatial health equity status; $b$ ) spatial health equity map derived by interpolating VGI.

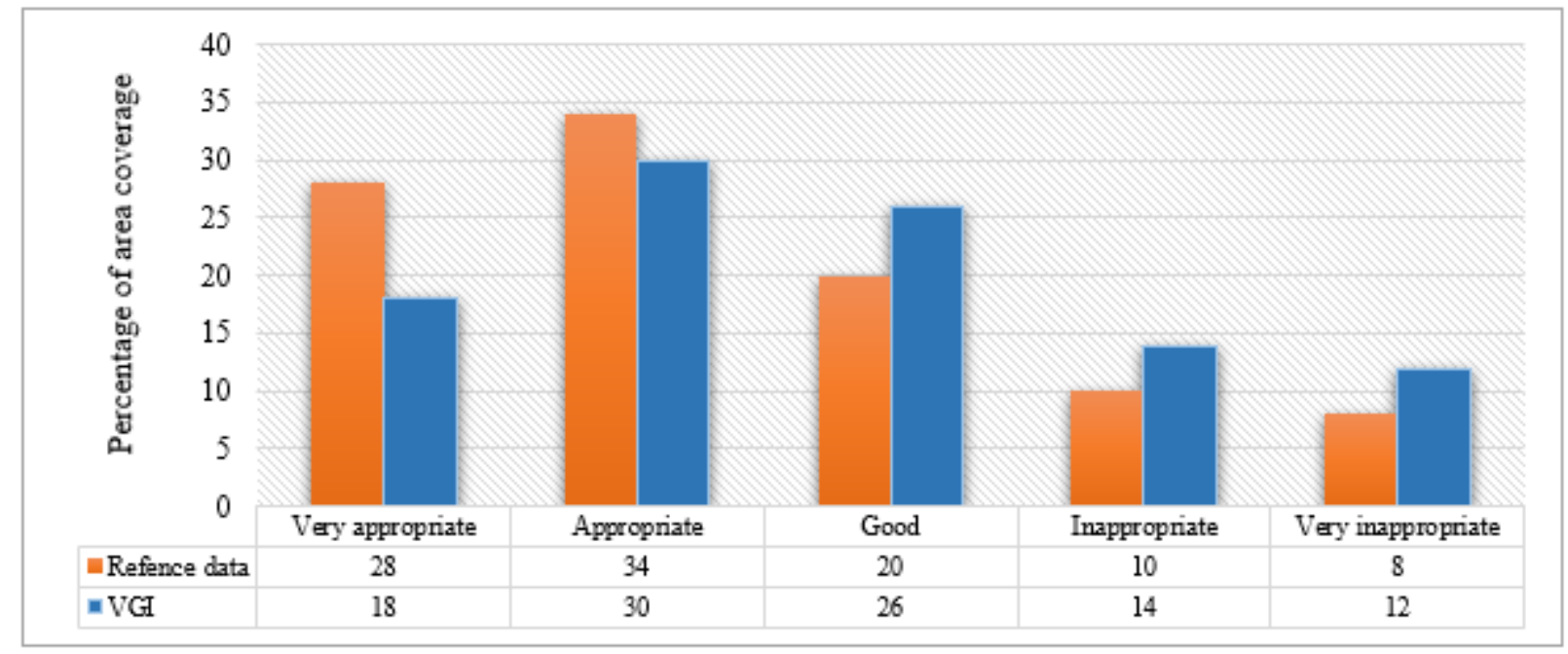

Figure 13

Comparison between the reference data and VGI. 